\title{
BOOK-TAX DIFFERENCES E RATING
}

\section{BOOK-TAX DIFFERENCES AND RATING}

\section{DIFERENCIAS DE IMPUESTOS DE RESERVA E RATING}

Recebido em: 14-01-2020

Avaliado em: 02-04-2020

Reformulado em: 22-04-2020

Aceito para publicação em: 04-05-2020

Publicado em: 26-04-2021

Editor Responsável: Roberto Carlos Klann

\author{
Josilene da Silva Barbosa ${ }^{1}$ \\ Patrícia de Souza Costa ${ }^{2}$
}

\section{RESUMO}

O estudo tem como objetivo verificar a relação dos diferentes tipos e níveis de Book-Tax Differences (BTD) com as notas de rating. Crabtree e Maher (2009) documentaram relação negativa entre o rating e as BTD total e temporária e conjecturam que as empresas irão gerenciar o resultado de forma a manter uma distância equilibrada entre o lucro contábil e o tributável, para não afetar negativamente as notas de rating. Esses autores analisaram apenas dois tipos de BTD, mas o rating pode ter relação com todos os tipos, principalmente, aqueles relacionados com o gerenciamento de resultados. Assim, o estudo busca ultrapassar as fronteiras do conhecimento acerca da relação entre os diferentes tipos de BTD e o rating. Justifica-se ao demonstrar quais tipos e níveis de BTD podem ser interpretados de forma positiva pelas agências de rating, favorecendo as classificações de crédito, e quais tipos podem ser interpretados como um sinal de alerta, gerando ratings menores. A amostra é composta por 3.737 observações de companhias abertas de 54 países do período de 2001 a 2016. Os dados foram analisados por meio de regressão logística. Os testes econométricos envolveram os diferentes tipos de BTD (total, positiva, negativa, anormal, normal, permanente e temporária) segregados por quintis. Os resultados sugerem que a BTD tem conteúdo informacional útil às agências de rating em suas avaliações de risco de crédito. Demonstram ainda que são os níveis elevados de BTD que afetam negativamente o rating, enquanto a menor distância entre as duas medidas de lucro parece não indicar uma preocupação para as agências de rating, não afetando suas avaliações. Acredita-se que os resultados têm contribuição prática, ao sugerir que a manipulação dos números contábeis pode gerar consequências negativas para as empresas, destacando-se que os gestores precisam ficar atentos quanto aos reflexos das escolhas contábeis, especificamente, no que tange aos valores contábeis que afetam a BTD.

Palavras-chave: Rating; Book-Tax Differences; Gerenciamento de resultados; Rating; IFRS.

\footnotetext{
${ }^{1}$ Doutora em Ciências Contábeis pela Universidade Federal de Uberlândia - UFU; Professora adjunta do curso de Ciências Contábeis (FACES) da Universidade Federal de Uberlândia - UFU; E-mail: josilene@ufu.br

${ }^{2}$ Doutora em Ciências Contábeis pela Universidade de São Paulo - USP; Professora adjunta do curso de Ciências

Contábeis da Universidade Federal de Uberlândia - UFU; E-mail: patricia.costa@ufu.br
} 


\section{ABSTRACT}

The study aims to verify a relationship of the different types and levels of Tax Differences on Books (BTD) with the classification notes. Crabtree and Maher (2009) documented the negative relationship between classification and how total and temporary BTD and what companies can manage or result in maintaining a balanced distance between accounting and taxable profit as it does not adversely affect how rating notes. These authors analyzed only two types of BTD, but the classification can be related to all types, mainly related to earnings management. Thus, the study seeks to overcome the frontiers of knowledge about the relationship between different types of BTD and the classification and justification, if demonstrating the types and levels of BTD can be interpreted positively by the rating agencies, favoring credit assessments and which types can be interpreted as a warning signal, generating lower classifications. A sample comprises 3,737 publicly traded organizations from 54 countries between 2001 and 2016 through logistic regression. Economic tests involve the different types of BTD (total, positive, negative, abnormal, normal, permanent, and temporary) segregated by quintiles. The results suggested for BTD have informative content useful to credit rating agencies, and show which are the high levels of BTD that negatively affect the rating. Simultaneously, the shorter distance between the two profit measures does not seem to indicate a concern for rating agencies and therefore end up not affecting your estimates. It is believed that the results obtained with the application of best practices and the manipulation of accounting numbers can generate negative effects for companies, highlighting that managers need to be aware of the consequences of accounting choices, which are not valid for values that affect a BTD.

Keywords: Rating; Book-Tax Differences; Earnings management; Rating; IFRS.

\section{RESUMEN}

El estudio tiene como objetivo verificar una relación de los diferentes tipos y niveles de diferencias fiscales en los libros (BTD) con las notas de clasificación. Crabtree y Maher (2009) documentaron la relación negativa entre la clasificación y la forma total y temporal de BTD y lo que las empresas pueden administrar o dar como resultado cómo mantener una distancia equilibrada entre las ganancias contables y gravables, ya que no afecta negativamente la calificación de las notas. Estos autores analizaron solo dos tipos de BTD, pero la clasificación puede estar relacionada con todos los tipos, principalmente relacionados con la gestión de ingresos. Por lo tanto, el estudio busca superar las fronteras del conocimiento sobre la relación entre los diferentes tipos de BTD y la clasificación y justificación, si las agencias calificadoras pueden interpretar positivamente los tipos y niveles de BTD, favoreciendo las evaluaciones crediticias y qué tipos se pueden interpretar como una señal de advertencia, generando clasificaciones más bajas. Una muestra está compuesta por 3.737 organizaciones que cotizan en bolsa de 54 países entre 2001 y 2016 a través de la regresión logística. Las pruebas económicas involucran los diferentes tipos de BTD (total, positivo, negativo, anormal, normal, permanente y temporal) segregados por quintiles. Los resultados sugeridos para BTD tienen contenido informativo útil para las agencias de calificación crediticia, además de mostrar cuáles son los altos niveles de BTD que afectan negativamente la calificación, mientras que la distancia más corta entre las dos medidas de ganancias no parece indicar una preocupación. para agencias de calificación y, por lo tanto, terminan sin afectar sus estimaciones. Se cree que los resultados obtenidos con la aplicación de las mejores prácticas y la manipulación de los números contables pueden generar efectos negativos para las empresas, destacando que los gerentes deben ser conscientes de las consecuencias de las elecciones contables, que no son válidas para los valores. que afectan a un BTD.

Palabras-clave: Calificación; Diferencias con el impuesto al libro; Gestión de resultados; IFRS. 


\section{INTRODUÇÃO}

Alguns escândalos contábeis, como os casos da Enron, WorldCom, Xerox, dentre outros, proporcionaram aos credores, investidores e formuladores de políticas uma atenção maior quanto à qualidade dos lucros divulgados pelas empresas. Diante desse contexto, Crabtree e Maher (2009) se propuseram a verificar se as agências de rating incorporavam em suas avaliações de risco de crédito as informações refletidas pela Book-Tax Differences (BTD). As evidências demonstraram que grandes valores de BTD temporária, tanto negativa quanto positiva, podiam afetar negativamente $o$ rating, bem como pequenos e grandes valores de BTD total também aumentavam a probabilidade de as empresas obterem notas de rating menores.

Embora Crabtree e Maher (2009) tenham documentado relação negativa entre rating e BTD, é possível identificar algumas lacunas sobre o tema. Primeiramente, os autores testaram apenas a BTD total e a BTD temporária positiva e negativa. Entretanto, acredita-se que seja relevante analisar os demais tipos de BTD, inclusive, para demonstrar se as agências de rating observam todos os tipos de BTD, já que cada uma possui suas características e peculiaridades (Chan, Lin, \& Mo, 2010; Tang \& Firth, 2011; Martinez \& Passamani, 2014). Por exemplo, a BTD normal é resultante das diferenças entre as normas fiscal e societária, enquanto a BTD anormal é derivada do gerenciamento de resultados (Tang, 2006). Assim, espera-se uma relação negativa entre a BTD anormal e o rating e uma relação positiva deste com a BTD normal. Pesquisas prévias demonstram que é relevante segregar a BTD por tipos, uma vez que tal medida implica em resultados distintos e, portanto, pode gerar consequências diversas (Costa \& Lopes, 2015; Santos, Costa, \& Silva, 2016; Fonseca \& Costa, 2017).

Em segundo lugar, quando testaram a BTD total, Crabtree e Maher (2009) utilizaram uma medida em que o lucro tributável é maior que o lucro contábil. Assim, os achados de Crabtree e Maher (2009), ao evidenciarem uma relação negativa entre grandes e pequenos níveis de BTD total (lucro tributável maior que o lucro contábil), sugerem que as agências de rating não penalizam apenas as empresas que relatam lucro tributável baixo (o que poderia indicar evasão físcal), mas também empresas que divulgam lucro tributável elevado (o que sugere falta de planejamento tributário). Isso significa que as agências de rating observam a distância entre as duas medidas de lucro (contábil e tributável), sendo necessário, portanto, analisar quando a empresa divulga pequenos e grandes valores de lucro contábil em relação ao tributável. Isso permitirá verificar se quando o lucro contábil é maior que o lucro tributável, também há consequências negativas se a empresa divulga grandes valores de BTD. Em terceiro lugar, quando analisaram a BTD temporária negativa e positiva, Crabtree e Maher (2009) não testaram os valores próximos de zero, ou seja, analisaram apenas os valores distantes de zero.

Crabtree e Maher (2009) conjecturam que as empresas irão gerenciar o resultado de forma a manter uma distância equilibrada entre o lucro contábil e o tributável, de modo que se a empresa mantiver a BTD distante da média do setor, poderá gerar impactos negativos no rating. Contudo, acredita-se que é preciso cautela ao analisar os diferentes níveis de BTD, pois a interpretação a respeito da BTD anormal em relação aos níveis, por exemplo, pode ser um pouco divergente. Dafydd e Jong-seo (2016) consideram que menores níveis de gerenciamento de resultados podem ser vistos pelas agências de rating de crédito como uma governança corporativa forte e, em consequência, informações contábeis confiáveis. Assim, é possível esperar que menores níveis de BTD anormal indiquem algo positivo e, portanto, podem gerar notas de rating melhores. Além disso, pesquisas prévias demonstram resultados e implicações divergentes quando se investiga, separadamente, cada tipo de BTD (Costa \& Lopes, 2015; Santos et al., 2016; Fonseca \& Costa, 2017).

Diante do exposto, pretende-se, no presente estudo, ampliar as discussões de Crabtree e Maher (2009) e fornecer informações adicionais sobre a relação entre rating e BTD. Com isso, o estudo busca ultrapassar as fronteiras do conhecimento acerca da relação entre os diferentes tipos de BTD e 
o rating. Assim, o objetivo geral da pesquisa é verificar a relação entre os diferentes tipos e níveis de BTD e as notas de rating.

Espera-se contribuir com a literatura ao demonstrar quais tipos e níveis de BTD podem ser interpretados de forma positiva pelas agências de rating, favorecendo as classificações de crédito; e quais tipos de BTD podem ser interpretados como um sinal de alerta, gerando rating menores. A relação entre BTD e rating é esperada, pois, acredita-se que há incentivo dos gestores em manipular os resultados da empresa em virtude dos ratings, o que pode ser compreendido a partir da Teoria Contratual da Firma (Jensen \& Mecking, 1976). Dessa forma, as agências de rating, na figura de intermediários da informação, buscariam monitorar as empresas, uma vez que seus gestores poderiam agir oportunisticamente em relação aos números contábeis (Lopes \& Martins, 2005). A BTD como sinal de alerta pode ser sustentada pela Teoria da Sinalização, a qual permite explicar como as agentes de mercado interpretam as informações disponíveis em ambiente de assimetria (Spence, 1973).

A pesquisa avança em termos científicos e sua contribuição teórica perpassa por acrescentar detalhes sobre a associação entre rating e BTD previamente documentada por Crabtree e Maher (2009), uma vez que são testados os diferentes tipos de BTD e segregados em quintil alto e baixo do setor, representando os grandes e pequenos valores de BTD, respectivamente. Conforme sugerido por Fields, Lys e Vincent (2001), é relevante investigar se a gestão da divulgação financeira é bem sucedida e quais são os reflexos econômicos e consequências das escolhas contábeis. Embora a presente pesquisa não se centra em realizar essa investigação diretamente, destaca-se que, ao demonstrar a relação entre os tipos e níveis de BTD e o rating, é possível dizer, indiretamente, que a empresa, ao apresentar determinado nível e tipo de BTD, poderá se deparar com consequências econômicas, especificamente, reflexos sobre o rating. Assim, os resultados encontrados se traduzem em uma contribuição prática que poderá ser útil aos gestores e, consequentemente, alertá-los que é preciso ter precaução quanto à divulgação dos números que envolvem os diferentes tipos de BTD.

Os resultados contribuirão com os investidores e outros usuários da informação contábil, os quais poderão utilizar a BTD para avaliar a qualidade dos números contábeis. Alinhado a isso, esperase que os achados da pesquisa sejam de interesse dos investidores, os quais poderão, diante do conhecimento sobre a relação entre BTD e rating, demonstrar insatisfação ou descontentamento sobre a qualidade com que o lucro contábil e o tributável estejam sendo apurados pelas empresas. Os achados podem ser úteis aos órgãos fiscais, no sentido de demonstrar que a BTD pode sinalizar incoerência com a forma de apuração do lucro tributável. Por fim, os resultados desta pesquisa também podem ser úteis a pesquisadores que buscam explicação sobre a relação entre rating e BTD, uma vez que esses podem avançar nas investigações sobre o tema.

\section{REFERENCIAL TEÓRICO E DESENVOLVIMENTO DE HIPÓTESES}

O rating é uma medida de risco que reflete a opinião das agências de classificação de risco a respeito da probabilidade de inadimplência de determinada empresa. As agências de rating baseiam suas avaliações, considerando, entre outras, informações extraídas das demonstrações financeiras e do mercado (Bouzouita \& Young, 1998; Sheng, 2005). Assim, expressa-se, por meio do rating, a capacidade da empresa em cumprir com suas obrigações financeiras (Bouzouita \& Young, 1998; Sheng, 2005). Quanto mais baixa for a classificação de rating, maior será o risco e, consequentemente, a taxa de juros requerida por investidores/credores, o que implica em maior custo na obtenção de recursos de capital (Kim \& Gu, 2004, Sheng, 2005). Sem a obtenção de uma avaliação das agências de rating, a obtenção de recursos, principalmente, por meio de dívidas, se torna mais difícil no mercado (Damasceno, Artes, \& Minardi, 2008). Por essas questões, o rating é visto como uma variável de interesse e preocupação por parte dos gestores (Kisgen, 2006).

Conjectura-se que as empresas irão gerenciar o resultado de forma a manter uma distância equilibrada (não muito distante e nem tão próximo) entre o lucro contábil e o tributável, para não afetar negativamente as notas de rating (Crabtree \& Maher, 2009). Isso porque elas evitariam chamar 
a atenção dos reguladores fiscais, caso divulgassem um lucro tributável menor e distante do lucro contábil, uma vez que tal situação poderia sugerir um planejamento fiscal agressivo e/ou gerenciamento do lucro contábil, para torná-lo maior, por parte das empresas (Crabtree \& Maher, 2009; Chan et al., 2010). Do mesmo modo, as empresas também evitariam contrariar o mercado divulgando um lucro tributável próximo do lucro contábil, pois isso poderia indicar planejamento fiscal inadequado, gerando pagamento elevado de impostos e impactos negativos no caixa e na situação financeira da empresa (Crabtree \& Maher, 2009).

O incentivo dos gestores em manipular os resultados da empresa em virtude dos ratings pode ser compreendido a partir da Teoria Contratual da Firma, a qual considera que as empresas são tidas como um conjunto de contratos estabelecidos entre os diversos participantes (stakeholders). Cada parte cumpre com sua participação e recebe algo em troca (Jensen \& Mecking, 1976). A relação contratual pode ser estabelecida de forma explícita ou implícita (Lopes \& Martins, 2005) e envolver os números contábeis. No entanto, a eficiência desses contratos depende do acesso e do quanto são confiáveis as informações contábeis (Dantas, Paulo, \& Medeiros, 2013). Nesse ponto específico, surge a figura dos intermediários da informação, representados pelos auditores, analistas de mercado de capitais e empresas de rating, os quais agem como monitores dos gestores em relação aos dados contábeis (Lopes \& Martins, 2005). Por isso, exercem pressão sobre a administração (Healy \& Palepu, 2001).

A BTD pode surgir em decorrência de três fatores: (a) diferenças legítimas nas normas contábeis em relação às regras fiscais; (b) discrição dos gestores no relatório financeiro para exagerar o lucro contábil; e/ou (c) os gestores poderão se aproveitar da ambiguidade nas regras fiscais para subestimar o lucro tributável (Chan et al., 2010). Assim, a BTD pode se dividir entre BTD nãodiscricionárias (BTD normal - BTDN) e BTD discricionárias (BTD anormal - BTDAN). A BTDAN ocorre devido a ações oportunistas dos gestores a partir do gerenciamento de resultados financeiro e/ou fiscal. Os gestores podem manipular o lucro tributável com o objetivo de enganar as autoridades fiscais, reduzindo os tributos a serem pagos, ou quando manipulam o lucro contábil para enganar os acionistas. Ferreira, Martinez, Costa e Passamani (2012) demonstraram que havia uma relação diretamente proporcional entre os valores da BTD e o gerenciamento de resultados medido pelos accruals discricionários. Em suma, os achados revelaram que o gerenciamento de resultados nas empresas tendia a ocorrer na mesma direção que a BTD. Tang e Firth (2011) também demonstraram que o gerenciamento de resultados era capaz de explicar uma parcela da BTD, ou seja, as duas variáveis estavam positivamente relacionadas. Nesse sentido, considerando os pressupostos da Teoria da Sinalização, de que os agentes de mercado interpretam as informações disponíveis em ambiente de assimetria (Spence, 1973), é possível esperar que a BTD seja vista pelas agências de rating como uma variável capaz de sinalizar a qualidade dos números contábeis.

Os estudos de Alissa, Bonsall Iv, Koharki e Penn Jr (2013), Kim, Kim e Song (2013), Demirtas e Cornaggia (2013), Brown, Chen e Kim (2015), Dafydd e Jong-seo (2016) e Sibim (2017) confirmam que os gestores são incentivados a se engajarem em atividades de gerenciamento de resultados como forma de influenciar a emissão das notas de rating por parte das agências. Blume, Lim e Craig MacKinlay (1998) consideram que os gestores podem aproveitar do fato de que as agências de rating dependem das informações financeiras divulgadas para, assim, gerenciarem os resultados. Além disso, no levantamento realizado por Graham e Harvey (2001), os gestores afirmaram que, dentre as decisões relacionadas com a estrutura de capital, buscavam priorizar aquelas favoráveis às classificações de rating. Fields et al. (2001) acrescentam que, entre os incentivos dos gestores quanto ao gerenciamento de resultados, encontram-se a perspectiva de melhora na precificação das ações e dos títulos no mercado, além da redução da variação do lucro, da percepção dos riscos e incertezas dos analistas e investidores (Fields et al., 2001).

Contudo, os achados de Dafydd e Jong-seo (2016) demonstraram que nem sempre o gerenciamento de resultados poderá gerar um efeito positivo sobre as notas de rating, bem como as empresas que realizam tal gerenciamento não experimentam um aumento de rating de crédito. Pelo 
contrário, tais empresas têm mais probabilidade de sofrerem uma redução no rating. Dafydd e Jongseo (2016) consideram que menores níveis de gerenciamento de resultados podem ser vistos pelas agências de rating de crédito como uma governança corporativa forte e, em consequência, informações contábeis confiáveis.

Com base em tais evidências e nas explicações teóricas já discutidas sobre os incentivos dos gestores em gerenciar o resultado em função do rating, acredita-se que a associação negativa entre grandes valores da BTD e rating, documentada por Crabtree e Maher (2009), ocorre, na verdade, devido à parcela discricionária da BTD. Assim, considerando que os gestores são motivados a gerenciar os resultados e que nem sempre o gerenciamento surte um efeito positivo no rating (Dafydd \& Jong-Seo, 2016), pretende-se investigar até que ponto a BTD está associada ao rating e até que ponto essa associação pode ser positiva ou negativa.

Para tanto, a BTD no quintil baixo do setor (lucro contábil menor que lucro tributável, porém com uma distância pequena entre ambos) representa que a empresa não está envolvida em atividades agressivas de gerenciamento tributável e/ou contábil. Caso estivesse, poderia chamar a atenção do fisco e, com isso, gerar multas e futuros desembolsos de caixa, comprometendo a situação financeira da empresa (Crabtree \& Maher, 2009). Já a BTD no quintil alto do setor sugere que a empresa está envolvida em fortes atividades de gerenciamento de resultados. Portanto, é possível visualizar que menores distâncias entre o lucro contábil e o tributável (BTD concentrada no quintil baixo do setor) podem ser vistas como algo positivo pelas agências de rating, ao passo que maiores distâncias entre o lucro contábil e o tributável podem ser vistas como algo negativo por essas agências. Em suma, as agências de rating incorporam as informações da BTD em suas avaliações de risco de crédito, formulando-se, assim, a seguinte hipótese de pesquisa:

H1: Empresas com maiores níveis de BTD têm maior probabilidade de obter menores notas de rating do que as empresas com menores níveis de BTD.

\section{PROCEDIMENTOS METODOLÓGICOS}

A população alvo é composta por 48.010 empresas dos 93 países com dados disponíveis na base da Capital IQ (Tabela 1), o que totaliza 768.160 observações entre os anos de 2001 a 2016. Da referida população, algumas empresas foram excluídas por não haver classificação de setor. Seguindo Alves e Ferreira (2011) e Edwards, Schwab e Shevlin (2016), também se optou por excluir as empresas do setor financeiro, pois elas estão sujeitas a regulamentos específicos que podem influenciar o nível de BTD e demais variáveis. Além disso, Bis e Martinez (2017) explicam que as empresas do setor financeiro atuam sob diferentes regras de tributação e registros contábeis, o que pode causar viés no cálculo da BTD.

\section{Tabela 1}

Amostra de pesquisa

\begin{tabular}{lc}
\hline \multicolumn{1}{c}{ Critérios de definição amostral } & Observações \\
\hline Amostra inicial 48.010 empresas & 768.160 \\
(-) Empresas sem classificação do setor & $(5.280)$ \\
(-) Empresas do setor financeiro & $(84.336)$ \\
(-) Empresas do país Romênia devido à superinflação entre 2001 a 2005 & $(1.168)$ \\
(-) Empresas dos países Barém e Bermuda por não terem tributação sobre a renda & $(752)$ \\
(-) Empresas dos países Costa do Marfim e Palestina, pois não foi encontrada a alíquota de IR & $(1.424)$ \\
(-) Empresas sem dados para o cálculo da BTD & $(463.932)$ \\
(-) Empresas nos anos em que o LAIR é negativo & $(41.589)$ \\
(-) Empresas sem rating & $(165.942)$ \\
\hline Total & 3.737 \\
\hline
\end{tabular}

Fonte: dados da pesquisa 
Foi excluída a Romênia devido à superinflação entre 2001 a 2005, tendo sido excluídas também as empresas dos países Barém e Bermuda, por não terem tributação sobre a renda, o que impediria o cálculo da $B T D$. Ainda, foram excluídas as empresas dos países Costa do Marfim e Palestina, pois não foram encontradas suas respectivas alíquotas de imposto de renda (IR). Em seguida, foram excluídas as empresas que não apresentavam dados para o cálculo da $B T D$. Além disso, ao se basear em Hanlon (2005) e Edwards et al. (2016), a BTD não foi calculada para os anos em que o Lucro antes da dedução do Imposto de renda (LAIR) era negativo. Hanlon (2005) explica que tal medida é necessária, pois os prejuízos fiscais podem se tornar ativos fiscais diferidos e, assim, podem ofuscar os efeitos da $B T D$ na conta de despesa com IR diferido. Por fim, foram excluídas as empresas com falta de rating, totalizando 165.942 observações. A amostra final foi definida por conveniência, ficando composta de 3.737 observações (Tabela 1) representada por 54 países (Tabela 2). Ressalta-se que os testes foram feitos separando a $B T D$ em quintil alto e baixo do setor. Por isso, no Tabela 2 consta a quantidade de observações segregadas por quintil alto e baixo, inclusive por país.

Tabela 2 - Amostra segregada por País

\begin{tabular}{|c|c|c|c|c|c|c|c|c|c|c|c|c|c|}
\hline \multirow{3}{*}{ País } & \multicolumn{6}{|c|}{ Observações } & \multirow{3}{*}{ País } & \multicolumn{6}{|c|}{ Observações } \\
\hline & \multicolumn{2}{|c|}{$\begin{array}{c}\text { Amostra } \\
\text { total }\end{array}$} & \multicolumn{2}{|c|}{$\begin{array}{l}\text { Quintil } \\
\text { alto }\end{array}$} & \multicolumn{2}{|c|}{$\begin{array}{l}\text { Quintil } \\
\text { baixo }\end{array}$} & & \multicolumn{2}{|c|}{$\begin{array}{c}\text { Amostra } \\
\text { total }\end{array}$} & \multicolumn{2}{|c|}{ Quintil alto } & \multicolumn{2}{|c|}{$\begin{array}{l}\text { Quintil } \\
\text { baixo }\end{array}$} \\
\hline & $\mathbf{N}$ & $\%$ & $\mathbf{N}$ & $\%$ & $\mathbf{N}$ & $\%$ & & $\mathbf{N}$ & $\%$ & $\mathbf{N}$ & $\%$ & $\mathbf{N}$ & $\%$ \\
\hline Argentina & 41 & 1,1 & 5 & 0,71 & 10 & 1,33 & Luxemburgo & 2 & 0,05 & 0 & 0,00 & 1 & 0,13 \\
\hline Austrália & 96 & 2,57 & 25 & 3,55 & 19 & 2,53 & Malásia & 30 & 0,8 & 8 & 1,14 & 6 & 0,80 \\
\hline Áustria & 17 & 0,45 & 2 & 0,28 & 3 & 0,40 & México & 94 & 2,52 & 17 & 2,41 & 20 & 2,66 \\
\hline Bélgica & 11 & 0,29 & 0 & 0,00 & 2 & 0,27 & Holanda & 46 & 1,23 & 7 & 0,99 & 5 & 0,66 \\
\hline Brasil & 84 & 2,25 & 21 & 2,98 & 20 & 2,66 & Nova Zelândia & 19 & 0,51 & 2 & 0,28 & 3 & 0,40 \\
\hline Bulgária & 3 & 0,08 & 1 & 0,14 & 0 & 0,00 & Noruega & 19 & 0,51 & 0 & 0,00 & 5 & 0,66 \\
\hline Canadá & 113 & 3,02 & 23 & 3,27 & 21 & 2,79 & Oman & 3 & 0,08 & 0 & 0,00 & 1 & 0,13 \\
\hline Chile & 29 & 0,78 & 2 & 0,28 & 8 & 1,06 & Paquistão & 2 & 0,05 & 0 & 0,00 & 0 & 0,00 \\
\hline China & 36 & 0,96 & 3 & 0,43 & 22 & 2,93 & Peru & 17 & 0,45 & 3 & 0,43 & 2 & 0,27 \\
\hline Colômbia & 9 & 0,24 & 2 & 0,28 & 2 & 0,27 & Filipinas & 15 & 0,4 & 2 & 0,28 & 3 & 0,40 \\
\hline $\begin{array}{l}\text { República } \\
\text { Checa }\end{array}$ & 8 & 0,21 & 0 & 0,00 & 1 & 0,13 & Polônia & 16 & 0,43 & 3 & 0,43 & 6 & 0,80 \\
\hline Dinamarca & 16 & 0,43 & 0 & 0,00 & 5 & 0,66 & Portugal & 51 & 0,56 & 1 & 0,14 & 6 & 0,80 \\
\hline Egito & 4 & 0,11 & 4 & 0,57 & 0 & 0,00 & Catar & 4 & 0,11 & 1 & 0,14 & 1 & 0,13 \\
\hline Finlândia & 19 & 0,51 & 1 & 0,14 & 4 & 0,53 & Rússia & 12 & 0,32 & 5 & 0,71 & 2 & 0,27 \\
\hline França & 154 & 4,12 & 4 & 0,57 & 53 & 7,05 & Singapore & 16 & 0,43 & 3 & 0,43 & 2 & 0,27 \\
\hline Alemanha & 152 & 4,07 & 4 & 0,57 & 65 & 8,64 & África do Sul & 13 & 0,35 & 2 & 0,28 & 5 & 0,66 \\
\hline Grécia & 18 & 0,48 & 0 & 0,00 & 8 & 1,06 & Espanha & 62 & 1,66 & 5 & 0,71 & 21 & 2,79 \\
\hline Hong Kong & 309 & 8,27 & 57 & 8,10 & 46 & 6,12 & Sri Lanka & 8 & 0,21 & 0 & 0,00 & 2 & 0,27 \\
\hline Hungria & 2 & 0,05 & 0 & 0,00 & 0 & 0,00 & Suécia & 39 & 1,04 & 5 & 0,71 & 7 & 0,93 \\
\hline Índia & 49 & 1,31 & 19 & 2,70 & 7 & 0,93 & Suíça & 38 & 1,02 & 11 & 1,56 & 4 & 0,53 \\
\hline Indonésia & 86 & 2,3 & 12 & 1,70 & 18 & 2,39 & Taiwan & 26 & 0,7 & 9 & 1,28 & 4 & 0,53 \\
\hline Irlanda & 10 & 0,27 & 5 & 0,71 & 2 & 0,27 & Tailândia & 30 & 0,8 & 3 & 0,43 & 7 & 0,93 \\
\hline Israel & 6 & 0,16 & 1 & 0,14 & 1 & 0,13 & Trindade e Tobago & 2 & 0,05 & 1 & 0,14 & 0 & 0,00 \\
\hline Itália & 65 & 1,74 & 1 & 0,14 & 15 & 1,99 & Turquia & 26 & 0,7 & 6 & 0,85 & 2 & 0,27 \\
\hline Japão & 319 & 8,54 & 48 & 6,82 & 72 & 9,57 & $\begin{array}{l}\text { Emirados Árabes } \\
\text { Unidos }\end{array}$ & 17 & 0,45 & 6 & 0,85 & 1 & 0,13 \\
\hline Cazaquistão & 11 & 0,29 & 1 & 0,14 & 1 & 0,13 & Reino Unido & 169 & 4,52 & 37 & 5,26 & 22 & 2,93 \\
\hline Lituânia & 6 & 0,16 & 1 & 0,14 & 0 & 0,00 & $\begin{array}{l}\text { Estados Unidos da } \\
\text { América }\end{array}$ & 1318 & 35,27 & 325 & 46,16 & 209 & 27,8 \\
\hline & & & & Total & & & & 3737 & 100 & 704 & 100 & 752 & 100 \\
\hline
\end{tabular}

Nota: N: valor absoluto; \%: valor relativo.

Fonte: dados da pesquisa.

O modelo apresentado na Equação 1 é definido para examinar se os tipos de $B T D$ estão associados ao rating. 


$$
\begin{aligned}
\text { RATING }_{i t}= & \alpha+b_{1 i t} \text { BTD }_{1 i t}+b_{2 i t} T^{T A M_{2 i t}}+b_{3 i t} E_{N D_{3 i t}}+b_{4 i t} R O A_{4 i t}+b_{5 i t} \text { FCO }_{5 i t} \\
& +b_{6 i t} \text { TAN }_{6 i t}+b_{7 i t} \text { CRE }_{7 i t}+b_{8 i t} P I_{8 i t}+b_{9 i t} I F I N_{9 i t}+b_{10 i t} M E_{10 i t}+\varepsilon_{i t}
\end{aligned}
$$

Em que: i: empresas, t: anos, $\alpha$ : termo específico da regressão, e: erro residual da regressão. RATING: é testado o rating em escala ordinal de 1 a 22 e também como variável dummy que assume valor 1 se a empresa tem o rating no grau especulativo e 0 caso contrário. BTD: diferença entre o lucro contábil e tributável, a qual é testada por tipos (BTD total, negativa e positiva, anormal, normal, permanente, temporária), sendo separadas por quintil alto e baixo do setor. TAM: logaritmo natural do ativo total; END: dívidas totais dividida pelo ativo total; ROA: lucro operacional dividido pelo ativo total no ano t, FCO: fluxo de caixa operacional divido pelo ativo total; TAN: imobilizado no ano t dividido pelo $A T$ defasado em $t-1$; $C R E$ : variação das vendas entre os anos $t$ e $t$ - 1 , dividido pelas vendas no ano $t$-1; PI: provisão de créditos de liquidação duvidosa dividido por clientes; IFIN: patrimônio líquido divido pelo ativo total no ano t; ME: EBIT dividido pela receita líquida.

A variável dependente é o rating de crédito. As agências $S \& P$ e Fitch classificam as empresas por meio de uma codificação representada por letras, que indicam desde uma forte até uma fraca capacidade de pagamentos financeiros (Miiller \& Martinez, 2016). São 22 classificações no total, tendo um rating classificado como "AAA" a classificação mais alta atribuída pelas agências. Nesse caso, a capacidade do devedor para cumprir seu compromisso financeiro com a obrigação é extremamente forte. Por outro lado, a classificação mais baixa é representada pela letra "D", o que indica a pior situação financeira (S\&P Global, 2016). Em conformidade com o estudo de Silva, Santos e Almeida (2012), foram utilizados os ratings tanto da $S \& P$ quanto o da Fitch, optando-se, nos casos em que havia divergência de classificação entre as duas agências, por escolher o rating da $S \& P$, por ser essa agência mais renomada no mercado. Seguindo o estudo de Ayers, Laplante e Mcguire (2010) e Crabtree e Maher (2009), quando as empresas tinham mais de um rating no mesmo ano, optou-se por escolher a última classificação do ano.

\begin{tabular}{|c|c|c|c|}
\hline $\begin{array}{c}\text { Escala de rating da } \\
\text { S\&P }\end{array}$ & $\begin{array}{c}\text { Escala de rating da } \\
\text { Fitch }\end{array}$ & $\begin{array}{l}\text { Escala dos ratings em } \\
\text { valores numéricos }\end{array}$ & $\begin{array}{c}\text { Dummy para classificação dos } \\
\text { ratings }\end{array}$ \\
\hline $\mathrm{AAA}$ & AAA & 22 & \\
\hline $\mathrm{AA}+$ & $\mathrm{AA}+$ & 21 & \\
\hline AA & AA & 20 & \\
\hline AA- & AA- & 19 & \\
\hline $\mathrm{A}+$ & $A+$ & 18 & Grau de investimento - \\
\hline $\mathrm{A}$ & $\mathrm{A}$ & 17 & dummy com valor 0 \\
\hline A- & A- & 16 & \\
\hline $\mathrm{BBB}+$ & $\mathrm{BBB}+$ & 15 & \\
\hline $\mathrm{BBB}$ & $\mathrm{BBB}$ & 14 & \\
\hline BBB- & BBB- & 13 & \\
\hline $\mathrm{BB}+$ & $\mathrm{BB}+$ & 12 & \\
\hline $\mathrm{BB}$ & $\mathrm{BB}$ & 11 & \\
\hline BB- & BB- & 10 & \\
\hline $\mathrm{B}+$ & $\mathrm{B}+$ & 9 & \\
\hline $\mathrm{B}$ & $\mathrm{B}$ & 8 & \\
\hline B- & B- & 7 & Grau especulativo - \\
\hline $\mathrm{CCC}+$ & $\mathrm{CCC}+$ & 6 & dummy com valor 1 \\
\hline $\mathrm{CCC}$ & $\mathrm{CCC}$ & 5 & \\
\hline CCC- & CCC- & 4 & \\
\hline $\mathrm{CC}$ & $\mathrm{CC}$ & 3 & \\
\hline $\mathrm{C}$ & $\mathrm{C}$ & 2 & \\
\hline $\mathrm{D}$ & $\mathrm{D}$ & 1 & \\
\hline
\end{tabular}

Tabela 3 - Classificações de rating

Fonte: elaborado a partir de Crabtree e Maher (2009), Ayers et al. (2010) e Sibim (2017). 
Primeiramente, a tradução das letras dos ratings foi feita para números de 1 a 22 (Tabela 3), conforme metodologia utilizada por estudos prévios (Ayers et al., 2010; Miiller \& Martinez, 2016). Assim, um número maior indica uma classificação melhor. Seguindo as recomendações de Sibim (2017), uma segunda categoria também foi adotada e testada no presente estudo, tendo sido as notas de rating transformadas em uma variável dummy, em que 1 indica as empresas com classificações no grau especulativo e 0 , as empresas com rating no grau de investimento (Tabela 3 ).

A variável explicativa de interesse é a $B T D$. A Equação 1 foi testada para cada tipo de $B T D$, considerando ainda os valores extremos (quintil alto e baixo do setor). Para o cálculo das BTD total, temporária e permanente foi utilizada a metodologia proposta por Comprix, Graham e Moore (2011) e Costa e Lopes (2015), conforme as Equações 2, 3 e 4, respectivamente.

$$
\begin{gathered}
B T D T_{i t}=\frac{L A I R_{i t}-L T_{i t}}{A T_{i t-1}} \\
B T D T E_{i t}=\frac{D I R D_{i t} / A_{i t}}{A T_{i t-1}} \\
B T D P E_{i t}=B T D T_{i t}-B T D T E_{i t}
\end{gathered}
$$

Em que: BTDT é a diferença total entre o lucro contábil e o lucro tributável; LAIR é o lucro contábil antes do imposto de renda; $L T$ é o lucro tributável; $A T$ é ativo total no período $t-1$. BTDTE é a diferença temporária entre o lucro contábil e o lucro tributável; DIRD é a despesa com imposto de renda diferido; $A$ é a alíquota máxima de imposto de renda $(A)$ de cada país; e BTDPE é a diferença permanente entre o lucro contábil e o lucro tributável.

O lucro tributável ( $L T)$ foi calculado com base na metodologia utilizada por Hanlon (2005) e Costa e Lopes (2015). O LT é a relação entre a despesa de imposto de renda corrente (DIRC) e a alíquota máxima de imposto de renda $(A)$ de cada país. Plesko (1999) demonstrou empiricamente que essa estimativa do lucro tributável estava correlacionada com o real lucro tributável das empresas. Assim, embora o cálculo da BTD envolva uma limitação decorrente do cálculo indireto do lucro tributável, a sua estimativa, a partir de dados das demonstrações financeiras, pode ser vista como uma proxy segura (Plesko, 1999).

Para o cálculo da BTD anormal (BTDAN), foi utilizado o modelo de Tang (2006), com as adaptações propostas por Martinez e Passamani (2014) (Equação 5). Para o cálculo da BTD normal $(B T D N)$, foi utilizada a Equação 6.

$$
\begin{gathered}
B T D T_{i t}=\alpha+\beta 1 I N V_{i t}+\beta 2 \Delta R E V_{i t}+\beta 3 N O L_{i t}+\beta 4 D I R D_{i t}+\beta 5(P L-L L)_{i t} \\
+\beta 6 \Delta E S T_{i t}+\varepsilon_{i t} \\
B T D N_{i t}=B T D T_{i t}-B T D A N_{i t}
\end{gathered}
$$

Em que: $B T D T_{i t}$ é a diferença total entre o lucro contábil e o lucro tributável; INV é o somatório das contas investimentos, imobilizado, intangível e diferido (saldo remanescente da conta, caso exista) da empresa $i$ no ano $t ; \triangle R E V$ é a variação da receita da empresa i no ano $t-1$ para o ano $t$ (calculada pela diferença entre receita no ano $t$ e receita no ano $t-1) ; N O L=$ prejuízo fiscal compensado; $D I R D=$ despesas com imposto de renda diferido da empresa $i$ no ano $t ; P L-L L=$ valor do patrimônio líquido subtraído do lucro líquido da empresa $i$ no ano t; $\Delta \mathrm{EST}=$ variação dos estoques da empresa $\mathrm{i}$ no ano $\mathrm{t}$ (calculada pela diferença entre estoques no ano $t$ e estoques no ano $t-1$ ). Todas as variáveis foram escalonadas (divididas) pelo ativo total defasado em $t-1$ para controlar o tamanho da empresa. O resíduo (zit) da Equação 5 representa a $B T D$ anormal (BTDAN). A BTDN é a BTD normal e resulta da $B T D$ total (BTDT, apurada na Equação 2) menos a BTDAN identificada na Equação 5.

Para definir os quintis altos e baixos do setor, as $B T D$ total, temporária, permanente, anormal e normal foram colocadas em módulo (para rodar as regressões os valores foram mantidos com os respectivos sinais). Assim, os valores definidos para o quintil alto do setor (maiores valores de $B T D$ ) 
assumem tanto sinal positivo quanto negativo, pois trata-se dos valores da $B T D$ que estão distantes de zero $(B T D A S)$. Para a $B T D$ no quintil baixo do setor $(B T D B S)$, os valores são próximos de zero (menores valores de $B T D$ ) e têm sinal positivo ou negativo. Para a $B T D$ negativa e positiva, o quintil alto do setor também corresponde aos valores que estão distantes de zero (maior a diferença entre lucro contábil e tributável) e o quintil baixo do setor corresponde aos valores próximos de zero (menor a diferença entre lucro contábil e tributável). No entanto, para a BTD negativa, o quintil alto do setor indica que o lucro contábil é bem menor que o tributável; já a $B T D$ positiva indica que o lucro contábil é bem maior que o lucro tributável.

Tabela 4 - Determinantes do rating

\begin{tabular}{|c|c|c|c|}
\hline Variáveis & Fórmula & Sinal & Explicação da associação esperada \\
\hline ROA & ROAit $=\frac{\text { lucro operacional }_{i t}}{{\text { ativo } \text { total }_{i t}}}$ & + & $\begin{array}{l}\text { Quanto maior a rentabilidade, maior a capacidade da empresa em lidar } \\
\text { com situações econômicas desfavoráveis e imprevistas (Bouzouita \& } \\
\text { Young, 1998), maior a capacidade da empresa em honrar com suas } \\
\text { obrigações financeiras (Gray, Mirkovic, \& Ragunathan, 2006) e, } \\
\text { portanto, melhor tende a ser a classificação de rating. }\end{array}$ \\
\hline CRE & $C R E_{i t}=\frac{\text { vendas }_{i t}-\text { vendas }_{t-1}}{\text { ativo total }}$ & + & $\begin{array}{l}\text { Quanto maior o crescimento, mais forte tende a ser a situação financeira } \\
\text { da empresa e oportunidade para obter fluxos de caixas futuros (Adams, } \\
\text { Burton \& Hardwick, 2003) e, em consequência, garantir o pagamento } \\
\text { das dívidas e obter ratings melhores (Bouzouita \& Young, 1998). }\end{array}$ \\
\hline \multirow[t]{2}{*}{ TAN } & \multirow{2}{*}{ Tangibilidade $_{i t}=\frac{\text { imobilizado }_{i t}}{\text { ativo total }_{\text {it }-1}}$} & + & $\begin{array}{l}\text { Soares, Coutinho e Camargos (2012) consideram que os itens do } \\
\text { imobilizado podem servir como garantias nos contratos de dívidas e, } \\
\text { por isso, quanto maior o nível de tangibilidade da empresa, melhores } \\
\text { tendem a ser as notas de ratings. }\end{array}$ \\
\hline & & - & $\begin{array}{l}\text { O nível de tangibilidade pode afetar negativamente o rating, pois } \\
\text { apresentam baixo grau de liquidez, o que compromete o pagamento das } \\
\text { dívidas no prazo de vencimento (Soares et al., 2012). }\end{array}$ \\
\hline FCO & $\mathrm{FCO}_{i t}=\frac{\text { Fluxo de caixa operacional }_{i t}}{\text { ativo } \text { total }_{i t}}$ & + & $\begin{array}{l}\text { "Empresas com alto fluxo de caixa têm classificações mais altas por } \\
\text { causa do menor risco de falência" (Demirtas \& Cornaggia, 2013, p. } \\
139 \text { ). }\end{array}$ \\
\hline TAM & Tamanho $_{i t}=$ Ln ativo total $_{i t}$ & + & $\begin{array}{l}\text { Empresas maiores apresentam menor risco por terem melhores } \\
\text { condições de lidar com imprevistos econômicos que possam ser } \\
\text { negativos para o seu desempenho (Bouzouita \& Young, 1998; Kim \& } \\
\text { Gu, 2004). Além disso, "grandes companhias têm acesso mais } \\
\text { facilitado a crédito e são consideradas importantes para a economia de } \\
\text { um país, pois sustentam, em geral, um conjunto de outras empresas } \\
\text { menores. Assim, tendem a receber ajuda tanto do governo como de } \\
\text { outras firmas, em caso de necessidade" (Murcia, 2013, p. 93). }\end{array}$ \\
\hline END & $E N D_{i t}=\frac{\text { Dividas totais }_{i t}}{{\text { ativo } \text { total }_{i t}}}$ & + & $\begin{array}{l}\text { As dívidas são tidas como medida de risco, de modo que, quanto maior } \\
\text { as dívidas, maior tende a ser o risco das empresas e, por consequência, } \\
\text { são penalizadas nas notas de rating, pois isso compromete sua } \\
\text { capacidade de pagamento (Bouzouita \& Young, 1998; Murcia, 2013). }\end{array}$ \\
\hline PI & $\mathrm{PI}=\frac{\text { PCLD }_{\text {it }}}{\text { Clientes }_{\text {it }}}$ & - & $\begin{array}{l}\text { O nível de inadimplência dos clientes pode elevar o risco de crédito da } \\
\text { empresa, impactando no fluxo de caixa e na capacidade de pagamento } \\
\text { das obrigações (Lima, Fonseca, Silveira, Assaf Neto, 2018), além de } \\
\text { gerar problemas de solvência (Salvador et al., 2014). }\end{array}$ \\
\hline IFIN & IFIN $=\frac{\text { Patrimônio Líquido }_{\text {it }}}{\text { Ativo total }_{\text {it }}}$ & + & $\begin{array}{l}\text { O maior o nível de independência financeira da empresa indica que } \\
\text { menor tende a ser o nível de dívidas onerosas e, portanto, menor custo } \\
\text { de captação de recursos, o que pode reduzir o risco financeiro e, em } \\
\text { consequência, melhorar as notas de rating (Gomes Neto, 2017). }\end{array}$ \\
\hline ME & $\mathrm{ME}=\frac{\mathrm{EBIT}_{\mathrm{it}}}{\text { Receita Líquida }_{\mathrm{it}}}$ & + & $\begin{array}{l}\text { Quanto maior a margem EBIT, melhor a capacidade da empresa em } \\
\text { cumprir com as obrigações financeiras, imposto de renda e participação } \\
\text { dos acionistas (Soares et al., 2012). }\end{array}$ \\
\hline
\end{tabular}

Nota: TAM: tamanho; END: endividamento; ROA: retorno do ativo; FCO: fluxo de caixa operacional; TAN: tangibilidade; CRE: crescimento; PI: potencial de inadimplência; IFIN: independência financeira; ME: margem EBIT. Fonte: elaborado pelas autoras.

A coleta dos dados financeiros foi realizada por meio da base de dados Capital IQ, com exceção do LAIR, o qual foi coletado na Thomson Reuters. Já os ratings de crédito emitidos pelas 
agências Standard \& Poor's $(S \& P)$ e Fitch foram obtidos por meio da plataforma Bloomberg. Após efetuar todos os cálculos das variáveis, foi realizado o procedimento de winsorização ao nível de $5 \%$ para todas as variáveis das Equações de 1 a 5, cujo intuito foi mitigar o efeito dos outilers nas inferências dos resultados. O processo de winsorização também foi realizado nos estudos de Ayers et al. (2010) e Blaylock, Gaertner e Shevlin (2017).

Para efeito de comparação com os resultados da pesquisa de Crabtree e Maher (2009), os dados foram analisados por meio da regressão logística, uma vez que a variável dependente é não contínua (Equação 1). Quando a variável RATING, no modelo disposto na Equação 1, assume valores numéricos de 1 a 22, foi realizada a regressão logística ordenada. Quando o RATING é uma variável dummy, foi realizada a regressão logística. Os pressupostos de multicolinearidade do modelo ilustrado na Equação 1 foram testados por meio da estatística de Variance Inflation Factor (VIF). Em todos os testes o VIF apresentou média abaixo de 2,00 e valores inferiores a 6,00 para cada variável, o que sugere a inexistência de multicolinearidade para as variáveis do modelo (Fávero \& Belfiore, 2017). Foram também realizados três testes de especificação dos modelos, com a finalidade de detectar variáveis omitidas e endogeneidade: ovtest, linktest e ivreg. Os três testes atestam não haver problemas de variáveis omitidas. Além da observância dos resultados dos testes, procurou-se optar também por variáveis clássicas utilizadas na literatura, apresentadas no Tabela 4.

Com base em estudos prévios, outras variáveis de controle foram inseridas no modelo, pois apresentaram associação significante com a variável rating. A escolha das variáveis de controle se deu pelos seguintes critérios: a) explicação teórica a respeito da possível relação com o rating; e b) variáveis mais utilizadas na literatura como determinante do rating. Na Tabela 4 é demonstrada a explicação da associação esperada entre as variáveis de controle e o rating, bem como a forma de cálculo de tais variáveis.

\section{RESULTADOS E DISCUSSÕES}

\subsection{Análise descritiva}

Tabela 5 - Estatística descritiva das variáveis

\begin{tabular}{|c|c|c|c|c|c|c|c|c|}
\hline Variável & $\begin{array}{c}\text { Número de } \\
\text { observações }\end{array}$ & Média & $\begin{array}{l}\text { Desvio } \\
\text { padrão }\end{array}$ & Mínimo & Máximo & P25 & P50 & P75 \\
\hline RATING & 3.737 & - & - & 1 & 22 & 10 & 13 & 15 \\
\hline BTDTAS & 704 & 0,059 & 0,073 & $-0,082$ & 0,121 & 0,055 & 0,084 & 0,121 \\
\hline BTDTPOAS & 466 & 0,111 & 0,036 & 0,048 & 0,158 & 0,079 & 0,107 & 0,157 \\
\hline BTDTNEAS & 272 & $-0,096$ & 0,040 & $-0,153$ & $-0,041$ & $-0,153$ & $-0,087$ & $-0,062$ \\
\hline BTDANAS & 441 & 0,002 & 0,074 & $-0,077$ & 0,087 & $-0,073$ & $-0,042$ & 0,087 \\
\hline BTDNAS & 460 & 0,055 & 0,011 & 0,033 & 0,068 & 0,045 & 0,055 & 0,068 \\
\hline BTDPEAS & 685 & 0,040 & 0,076 & $-0,085$ & 0,110 & $-0,056$ & 0,070 & 0,110 \\
\hline BTDTEAS & 702 & 0,014 & 0,053 & $-0,053$ & 0,068 & $-0,051$ & 0,042 & 0,068 \\
\hline BTDTBS & 752 & 0,001 & 0,006 & $-0,016$ & 0,017 & $-0,004$ & 0,001 & 0,005 \\
\hline ВTDTPOBS & 475 & 0,006 & 0,003 & 0,003 & 0,018 & 0,003 & 0,005 & 0,008 \\
\hline BTDTNEBS & 279 & $-0,005$ & 0,004 & $-0,024$ & $-0,002$ & $-0,006$ & $-0,004$ & $-0,002$ \\
\hline BTDANBS & 468 & $-0,001$ & 0,006 & $-0,018$ & 0,015 & $-0,005$ & $-0,001$ & 0,003 \\
\hline BTDNBS & 468 & 0,004 & 0,007 & $-0,016$ & 0,016 & $-0,001$ & 0,006 & 0,009 \\
\hline BTDPEBS & 723 & 0,001 & 0,005 & $-0,017$ & 0,019 & $-0,002$ & 0,001 & 0,004 \\
\hline BTDTEBS & 723 & 0,000 & 0,003 & $-0,007$ & 0,007 & $-0,002$ & 0,000 & 0,002 \\
\hline TAM & 3.736 & 8,539 & 1,778 & 4,723 & 11,451 & 7,451 & 8,650 & 9847408,000 \\
\hline END & 3.736 & 0,326 & 0,169 & 0,034 & 0,639 & 0,201 & 0,322 & 0,447 \\
\hline ROA & 3.736 & 0,087 & 0,055 & 0,010 & 0,219 & 0,047 & 0,075 & 0,116 \\
\hline $\mathrm{FCO}$ & 3.734 & 0,095 & 0,064 & $-0,018$ & 0,234 & 0,053 & 0,087 & 0,134 \\
\hline TAN & 3.736 & 0,585 & 0,417 & 0,009 & 1,403 & 0,215 & 0,538 & 0,905 \\
\hline CRE & 3.737 & 0,066 & 0,137 & $-0,173$ & 0,395 & $-0,013$ & 0,042 & 0,132 \\
\hline PI & 2.682 & $-0,052$ & 0,066 & $-0,258$ & 0,000 & $-0,062$ & $-0,026$ & $-0,011$ \\
\hline IFIN & 3.736 & 0,414 & 0,177 & 0,119 & 0,773 & 0,285 & 0,400 & 0,530 \\
\hline ME & 2.459 & 0,021 & 0,057 & $-0,007$ & 0,232 & 0,000 & 0,000 & 0,007 \\
\hline
\end{tabular}

Nota: $R A T I N G$ é o rating em escala ordinal de 1 a 22. BTDTAS é a BTD total no quintil alto do setor. BTDTPOAS é a BTD total positiva no quintil alto do setor. $B T D T N E A S$ é a $B T D$ total negativa no quintil alto do setor. BTDANAS é a $B T D$ anormal no quintil alto do setor. $B T D N A S$ é a $B T D$ normal no quintil alto do setor. BTDPEAS é a $B T D$ permanente no quintil alto do setor. BTDTEAS é a BTD temporária 
no quintil alto do setor. $B T D T B S$ é a $B T D$ total no quintil baixo do setor. $B T D T P O B S$ é a $B T D$ total positiva no quintil baixo do setor. $B T D T N E B S$ é a $B T D$ total negativa no quintil baixo do setor. BTDANBS é a $B T D$ anormal no quintil baixo do setor. $B T D N B S$ é a $B T D$ normal no quintil baixo do setor. BTDPEBS é a $B T D$ permanente no quintil baixo do setor. BTDTEBS é a BTD temporária no quintil baixo do setor. TAM: logaritmo natural do ativo total; END: dívidas totais dividida pelo ativo total; ROA: lucro operacional dividido pelo ativo total no ano t, FCO: fluxo de caixa operacional divido pelo ativo total; TAN: imobilizado no ano t dividido pelo $A T$ defasado em $t$ - 1 ; $C R E$ variação das vendas entre os anos $t$ e $t$ - 1 , dividido pelas vendas no ano $t$ - 1 ; PI provisão de créditos de liquidação duvidosa dividido por clientes; IFIN: patrimônio líquido divido pelo ativo total no ano t; ME: EBIT dividido pela receita líquida.

Fonte: dados da pesquisa.

A estatística descritiva para as variáveis do estudo é apresentada na Tabela 5. A média das variáveis BTD é próxima de zero, consoante com os achados de Badertscher, Phillips, Pincus, \& Rego (2009), Frank, Lynch e Rego (2009) e Marques, Costa e Silva (2016).

Os resultados do teste de correlação de Spearman são apresentados na Tabela 6. Nesta pesquisa, adotam-se como resultado significativo as relações que apresentam nível de significância de $10 \%$. Os achados dos testes de correlação mostram indícios de que o RATING tem uma correlação negativa e significante com a BTD normal (coef. -0,170), BTD permanente (coef. -0,201) e BTD temporária (coef. -0,290), estando todas no quintil alto do setor. Isso sugere que, quanto maior a distância entre o lucro contábil e o tributável, menores tendem a ser as notas de rating. Este resultado corrobora a ideia de Crabtree e Maher (2009), de que os analistas de rating penalizam empresas com $B T D$ que estão distantes da média do setor.

Tabela 6 - Matriz de correlação

\begin{tabular}{|c|c|c|c|c|c|c|c|c|}
\hline & RATING & BTDTAS & BTDTPOAS & BTDTNEAS & BTDANAS & BTDNAS & BTDPEAS & BTDTEAS \\
\hline RATING & 1,000 & & & & & & & \\
\hline BTDTAS & 0,015 & 1,000 & & & & & & \\
\hline ВTDTPOAS & 0,005 & $0,975 * * *$ & 1,000 & & & & & \\
\hline BTDTNEAS & $-0,114$ & $0,893 * * *$ & - & 1,000 & & & & \\
\hline BTDANAS & $-0,040$ & $0,691 * * *$ & $0,732 * * *$ & $0,468 * * *$ & 1,000 & & & \\
\hline$B T D N A S$ & $-0,170^{*}$ & $0,573 * * *$ & $0,605 * * *$ & 0,800 & $0,405 * * *$ & 1,000 & & \\
\hline BTDPEAS & $-0,201 * *$ & $0,476 * * *$ & $0,697 * * *$ & $0,613 * * *$ & $0,921 * * *$ & $-0,552 * *$ & 1,000 & \\
\hline BTDTEAS & $-0,290 * *$ & $0,378 * * *$ & $0,341 * * *$ & 0,166 & 0,145 & $0,191^{*}$ & $-0,310 * * *$ & 1,000 \\
\hline BTDTBS & $-0,065$ & - & - & - & 0,090 & 0,237 & 0,105 & $-0,008$ \\
\hline ВTDTPOBS & 0,034 & - & - & - & $-0,258$ & 0,404 & 0,170 & $-0,351$ \\
\hline BTDTNEBS & $0,134 * *$ & - & - & - & 0,500 & 0,000 & $-0,038$ & 0,324 \\
\hline$B T D A N B S$ & $-0,152$ & $0,403 *$ & $0,409 *$ & - & - & 0,090 & 0,107 & 0,458 \\
\hline$B T D N B S$ & 0,135 & $0,461 * * *$ & 0,193 & $0,508 * * *$ & 0,105 & - & $-0,205$ & $-0,287$ \\
\hline BTDPEBS & 0,058 & $0,600 * * *$ & $0,546 * * *$ & $0,527 * *$ & $0,792 * * *$ & $0,226 * *$ & - & $0,371 * * *$ \\
\hline BTDTEBS & $-0,032$ & $-0,197 *$ & $-0,028$ & $-0,106$ & 0,050 & 0,010 & $-0,160$ & \\
\hline TAM & $0,459 * * *$ & $-0,173 * * *$ & $-0,210 * * *$ & $-0,041$ & $-0,078$ & $-0,287 * * *$ & $-0,426 * * *$ & 0,090 \\
\hline END & 0,001 & $-0,2445$ & $-0,2483 * * *$ & 0,116 & $0,261 * * *$ & $-0,256 * * *$ & $-0,312 * * *$ & 0,120 \\
\hline ROA & 0,011 & $0,180 * * *$ & $0,190 * * *$ & $-0,548 * * *$ & $-0,357 * * *$ & 0,100 & $0,197 * * *$ & 0,101 \\
\hline $\mathrm{FCO}$ & $0,087 * * *$ & $0,134 * *$ & $0,134 * *$ & $-0,454 * * *$ & $0,260 * * *$ & 0,058 & $0,178 *$ & $-0,225^{*}$ \\
\hline TAN & $0,142 * * *$ & $-0,260 * * *$ & $-0,261 * * *$ & $-0,187 * *$ & $-0,086$ & $-0,205^{* *}$ & $-0,204 * *$ & $-0,200$ \\
\hline CRE & $-0,029 *$ & $0,180 * * *$ & $0,178 * * *$ & $-0,256 * * *$ & $-0,294 * * *$ & $0,176^{*}$ & $0,201 * *$ & $-0,017$ \\
\hline PI & 0,023 & $-0,010$ & $-0,018$ & $-0,076$ & $-0,052$ & 0,090 & $-0,063$ & 0,131 \\
\hline IFIN & 0,025 & $0,193 * * *$ & $0,194 * * *$ & $-0,133$ & $-0,252 * * *$ & 0,110 & $0,209 * *$ & $-0,156$ \\
\hline $\mathrm{ME}$ & $-0,044 * *$ & 0,083 & $0,095^{*}$ & $-0,135$ & $-0,60$ & 0,101 & 0,110 & $0,330^{*}$ \\
\hline
\end{tabular}

Nota: $* * *, * *, *$ denotam significância estatística a $1 \%, 5 \%$ e $10 \%$, respectivamente. RATING é o rating em escala ordinal de 1 a 22. $B T D T A S$ é a BTD total no quintil alto do setor. BTDTPOAS é a BTD total positiva no quintil alto do setor. BTDTNEAS é a BTD total negativa no quintil alto do setor. BTDANAS é a BTD anormal no quintil alto do setor. BTDNAS é a BTD normal no quintil alto do setor. $B T D P E A S$ é a $B T D$ permanente no quintil alto do setor. BTDTEAS é a $B T D$ temporária no quintil alto do setor. BTDTBS é a $B T D$ total no quintil baixo do setor. $B T D T P O B S$ é a $B T D$ total positiva no quintil baixo do setor. BTDTNEBS é a $B T D$ total negativa no quintil baixo do setor. BTDANBS é a $B T D$ anormal no quintil baixo do setor. BTDNBS é a $B T D$ normal no quintil baixo do setor. $B T D P E B S$ é a $B T D$ permanente no quintil baixo do setor. BTDTEBS é a $B T D$ temporária no quintil baixo do setor. TAM: logaritmo natural do ativo total; END: dívidas totais dividida pelo ativo total; ROA: lucro operacional dividido pelo ativo total no ano t, FCO: fluxo de caixa operacional divido pelo ativo total; TAN: imobilizado no ano t dividido pelo AT defasado em $t-1$; $C R E$ variação das vendas entre os anos $t$ e $t$ - 1 , dividido pelas vendas no ano $t$ - 1 ; PI provisão de créditos de liquidação duvidosa dividido por clientes; IFIN: patrimônio líquido divido pelo ativo total no ano t; ME: EBIT dividido pela receita líquida. Fonte: dados da pesquisa.

Os achados indicam uma correlação positiva e significante para a BTD negativa (coef. 0,134 ) no quintil baixo do setor, sugerindo que, para esse tipo de BTD, quanto mais próximo o lucro contábil 
for do tributável, melhores serão as notas de rating. A BTD negativa no quintil baixo do setor significa que o lucro tributável é maior que o lucro contábil, porém, com uma pequena distância. Embora Crabtree e Maher (2009) argumentem que as empresas irão gerenciar o resultado de forma a manter uma distância equilibrada (não muito distante e nem tão próximo) entre o lucro contábil e o tributável, para não gerar rating baixo, tal correlação positiva sugere que as agências de rating não penalizam as empresas que divulgam BTD negativa no quintil baixo do setor. Isso porque, embora níveis baixos de BTDTNE possam indicar falta de planejamento tributário (Crabtree \& Maher, 2009), também podem sugerir que a empresa não está engajada em gerenciamento de resultado tributável agressivo, visto que, se estivesse, poderia chamar a atenção do fisco, gerar pagamento de multas e, assim, comprometer o caixa futuro da empresa (Crabtree \& Maher, 2009).

Em relação às correlações entre as demais variáveis de controle e o rating, de acordo com o esperado, o TAM apresenta indícios de correlação positiva e significante com o RATING (coef. 0,459). Esse resultado sugere que o tamanho da empresa se associa positivamente com as notas de rating, uma vez que empresas maiores apresentam menor risco, pois têm melhores condições de lidar com imprevistos financeiros (Bouzouita \& Young, 1998; Kim \& Gu, 2004), além de terem acesso mais facilitado a crédito (Murcia, 2013). Além disso, o FCO tem indícios de correlação positiva e significante com o RATING (coef. 0,087), o que sugere que "empresas com alto fluxo de caixa têm classificações mais altas por causa do menor risco de falência" (Demirtas \& Cornaggia, 2013, p. 139). $\mathrm{O}$ nível de tangibilidade também apresenta indícios de correlação positiva e significante com o RATING (coef. 0,142), corroborando os argumentos de Soares et al. (2012), de que os itens do imobilizado podem servir como garantia nos contratos de dívidas. Por isso, quanto maior o nível de tangibilidade da empresa, melhores tendem a ser as notas ratings.

A variável crescimento, contrário do esperado, demonstra indícios de correlação negativa e significante com o RATING (coef. -0,029). Isso significa que, quanto maior o nível de crescimento da empresa, menores tendem a ser as notas de rating. Tal achado contraria as evidências de que, quanto maior o crescimento, mais forte tende a ser a situação financeira da empresa; melhor a oportunidade para obter fluxos de caixas futuros (Adams et al., 2003); e, consequentemente, garantir o pagamento das dívidas e obter ratings melhores (Bouzouita \& Young, 1998). Já a margem EBIT, diferente do esperado, demonstra indícios de correlação negativa e significante com o RATING (coef. -0,044). Esse resultado é contrário ao pressuposto de que a margem EBIT, por demonstrar a facilidade de uma empresa em honrar com seus compromissos financeiros, despesas com imposto de renda e participações dos acionistas, estaria associada com notas maiores de rating (Soares et al., 2012).

Todos os índices de correlação das variáveis de controle com o rating foram abaixo de 0,6, o que indica correlação moderada ou baixa entre as variáveis (Fávero \& Belfiore, 2017). Portanto, em princípio, presume-se que as variáveis de controle podem exercer pouca influência nas avaliações das agências de rating quanto à classificação de crédito. Os testes econométricos são apresentados na seção 4.2, com o objetivo de analisar a relação entre as variáveis independentes e a dependente.

\subsection{Análise de regressão}

Na Tabela 7 são ilustrados os testes do modelo especificado na Equação 1, considerando a variável dependente RATING em escala ordinal (notas de 1 a 22) e os valores do quintil alto do setor para cada um dos tipos de $B T D$. Conforme o esperado, o rating tem relação negativa e significante com a BTDTAS (coef. - 4,018), BTDANAS (coef. -3,105), BTDNAS (coef. -19,425) e BTDPEAS (coef. $-3,466$ ), encontrando-se todas no quintil alto do setor. Esses resultados reforçam a ideia de Crabtree e Maher (2009), de que os analistas de rating penalizam empresas com grandes valores de BTD. No entanto, também demonstram, principalmente em relação à $B T D$ anormal, que nem sempre o gerenciamento de resultados poderá gerar um efeito positivo sobre as notas de rating (Dafydd \& JongSeo, 2016). Pelo contrário, as agências de rating penalizam as empresas com $B T D$ anormal no quintil alto do setor. Ao analisar a $B T D$ normal, é possível sugerir que, quando a empresa apresenta elevados níveis desse tipo de $B T D$, gera um sinal de alerta, de que os gestores poderiam ter se aproveitado 
oportunisticamente e gerenciado o lucro contábil e/ou tributável. Infere-se que as agências de rating buscam observar qualquer valor muito destoante da média do setor, interpretando como um sinal negativo.

Já para a BTDTPO no quintil alto do setor (coef. 7,340), a relação é positiva e significativa, ou seja, contrário do esperado. Esse resultado demonstra que, quanto maior o lucro contábil em relação ao tributável, melhores tendem a ser as notas de rating das empresas. Por sua vez, níveis elevados de $B T D$ positiva podem sugerir um planejamento fiscal agressivo e/ou gerenciamento do lucro contábil por parte das empresas (Crabtree \& Maher, 2009; Chan et al., 2010). Assim, os achados mostram que, no que se refere à $B T D T P O$, as agências de rating não parecem penalizar as empresas quando essas apresentam $B T D$ positiva distante da média do setor. Isso confirma que as evidências de Crabtree e Maher (2009) e Ayers et al. (2010) são concretas, ou seja, que a BTD tem conteúdo informacional útil às agências de rating em suas avaliações de risco de crédito. Porém, para a BTDTNE e BTDTE nos quintis altos do setor, os resultados não são significativos. Uma explicação para isso é que, talvez, na visão das agências de rating, tais $B T D$ não sejam um fator significante para impactar o rating, ou que as demais $B T D$ (as quais são significativas para explicar o rating) são suficientes e/ou mais relevantes.

Tabela 7 - Regressão logística ordenada - rating em escala ordinal e $B T D$ no quintil alto do setor RATING $_{\mathrm{it}}=\alpha+\mathrm{b}_{1 \mathrm{it}}$ BTDAS $_{1 \mathrm{it}}+\mathrm{b}_{2 \mathrm{it}} \mathrm{TAM}_{2 \mathrm{it}}+\mathrm{b}_{3 \mathrm{it}} \mathrm{END}_{3 \mathrm{it}}+\mathrm{b}_{4 \mathrm{it}} \mathrm{ROA}_{4 \mathrm{it}}+\mathrm{b}_{5 \mathrm{it}} \mathrm{FCO}_{5 \mathrm{it}}+\mathrm{b}_{6 \mathrm{it}} \mathrm{TAN}_{6 \mathrm{it}}+\mathrm{b}_{7 \mathrm{it}} \mathrm{CRE}_{7 \mathrm{it}}+\mathrm{b}_{8 \mathrm{it}} \mathrm{PI}_{8 \mathrm{it}}+$ $\mathrm{b}_{9 \mathrm{it}} \mathrm{IFIN}_{9 \mathrm{it}}+\mathrm{b}_{10 \mathrm{it}} \mathrm{ME}_{10 \mathrm{it}}+\mathrm{e}_{\mathrm{it}}$

\begin{tabular}{|c|c|c|c|c|c|c|c|c|c|}
\hline $\begin{array}{c}\text { Variáveis } \\
\text { explicativas }\end{array}$ & $\begin{array}{c}\text { Sinal } \\
\text { previsto }\end{array}$ & & $B T D T$ & ВТDTPO & BTDTNE & $B T D A N$ & $B T D N$ & $B T D P E$ & BTDTE \\
\hline \multirow{2}{*}{$B T D A S$} & \multirow[t]{2}{*}{$P=-100$} & beta & $-4,018$ & 7,340 & 0,662 & $-3,105$ & $-19,425$ & $-3,466$ & $-2,325$ \\
\hline & & p-valor & 0,003 & 0,041 & 0,899 & 0,031 & 0,049 & 0,013 & 0,223 \\
\hline \multirow{2}{*}{ TAM } & \multirow{2}{*}{+} & beta & 0,484 & 0,347 & 0,922 & 0,610 & 0,389 & 0,634 & 0,431 \\
\hline & & p-valor & 0,000 & $\mathbf{0 , 0 0 0}$ & 0,000 & 0,000 & 0,000 & 0,000 & 0,000 \\
\hline \multirow{2}{*}{ END } & \multirow{2}{*}{+} & beta & $-2,616$ & $-1,232$ & $-2,454$ & $-0,900$ & $-2,003$ & $-1,344$ & $-1,098$ \\
\hline & & p-valor & 0,007 & 0,293 & 0,123 & 0,383 & 0,029 & 0,170 & 0,234 \\
\hline \multirow{2}{*}{ ROA } & \multirow{2}{*}{+} & beta & $-1,490$ & $-2,124$ & 2,860 & $-0,064$ & $-2,703$ & 0,898 & $-0,295$ \\
\hline & & p-valor & 0,533 & 0,460 & 0,597 & 0,981 & 0,288 & 0,714 & 0,909 \\
\hline \multirow{2}{*}{$\mathrm{FCO}$} & \multirow[b]{2}{*}{+} & beta & 2,795 & 4,886 & $-0,271$ & 2,251 & 5,132 & 1,865 & 3,943 \\
\hline & & p-valor & 0,155 & 0,034 & 0,948 & 0,316 & 0,013 & 0,380 & 0,069 \\
\hline \multirow{2}{*}{ TAN } & \multirow{2}{*}{$+\mathrm{ou}-$} & beta & 0,384 & 0,205 & 1,060 & 0,905 & 0,020 & 1,056 & 0,255 \\
\hline & & p-valor & 0,143 & 0,533 & 0,001 & 0,001 & 0,942 & 0,000 & 0,306 \\
\hline \multirow{2}{*}{ CRE } & \multirow[b]{2}{*}{+} & beta & 0,693 & $-0,306$ & 0,124 & 0,549 & 0,856 & 0,604 & $-0,537$ \\
\hline & & p-valor & 0,269 & 0,696 & 0,918 & 0,406 & 0,210 & 0,360 & 0,419 \\
\hline \multirow{2}{*}{ PI } & & beta & 2,031 & 0,769 & 7,196 & 5,371 & 0,844 & 5,502 & 1,373 \\
\hline & & p-valor & 0,206 & 0,687 & 0,009 & 0,002 & 0,616 & $\mathbf{0 , 0 0 2}$ & 0,353 \\
\hline \multirow{2}{*}{ IFIN } & \multirow{2}{*}{+} & beta & 1,488 & 1,450 & 2,348 & 2,088 & 0,688 & 2,329 & 0,957 \\
\hline & & p-valor & 0,105 & 0,168 & 0,109 & $\mathbf{0 , 0 2 7}$ & 0,426 & 0,008 & 0,278 \\
\hline \multirow{2}{*}{$\mathrm{ME}$} & \multirow{2}{*}{+} & beta & 1,958 & 1,793 & 3,095 & 3,448 & 0,001 & 4,780 & 0,650 \\
\hline & & p-valor & 0,204 & 0,342 & 0,476 & 0,061 & 0,999 & 0,018 & 0,688 \\
\hline \multicolumn{3}{|c|}{ Likelihood Ratio } & $-867,023$ & $-570,722$ & $-263,241$ & $-768,594$ & $-832,562$ & $-808,284$ & $-834,932$ \\
\hline \multicolumn{3}{|l|}{ Prob $>\mathrm{F}$} & 0,000 & 0,000 & 0,000 & 0,000 & 0,000 & 0,000 & 0,000 \\
\hline \multicolumn{3}{|l|}{ Pseudo R2 } & 0,053 & 0,031 & 0,133 & 0,081 & 0,037 & 0,076 & 0,030 \\
\hline \multicolumn{3}{|c|}{ Número observações } & 351 & 229 & 117 & 316 & 335 & 329 & 341 \\
\hline
\end{tabular}

Nota: RATING é o rating em escala ordinal de 1 a 22. BTDTAS é a $B T D$ no quintil alto do setor. BTDT é a $B T D$ total no quintil alto do setor. $B T D T P O$ é a $B T D$ total positiva no quintil alto do setor. BTDTNE é a $B T D$ total negativa no quintil alto do setor. $B T D A N$ é a $B T D$ anormal no quintil alto do setor. $B T D N$ é a $B T D$ normal no quintil alto do setor. BTDPE é a $B T D$ permanente no quintil alto do setor. BTDTE é a BTD temporária no quintil alto do setor. TAM: logaritmo natural do ativo total; END: dívidas totais dividida pelo ativo total; ROA: lucro operacional dividido pelo ativo total no ano t, FCO: fluxo de caixa operacional divido pelo ativo total; TAN: imobilizado no ano t dividido pelo $A T$ defasado em $t-1$; $C R E$ variação das vendas entre os anos $t$ e $t$ - 1 , dividido pelas vendas no ano $t$ 1; PI provisão de créditos de liquidação duvidosa dividido por clientes; IFIN: patrimônio líquido divido pelo ativo total no ano t; ME: EBIT dividido pela receita líquida.

Fonte: dados da pesquisa. 
Em relação às variáveis de controle (Tabela 7), a única variável significante em todos os modelos (com os diferentes tipos de BTD no quintil alto do setor) para explicar o rating é o tamanho da empresa, a qual apresenta relação positiva e significativa ao nível de $1 \%$. Esse achado corrobora a correlação encontrada entre tais variáveis e confirma que o tamanho da empresa se associa positivamente com as notas de rating, demonstrando que empresas maiores apresentam menor risco, pois têm melhores condições de lidar com imprevistos financeiros (Bouzouita \& Young, 1998; Kim \& Gu, 2004), além de acesso mais facilitado ao crédito (Murcia, 2013).

Já quanto ao endividamento, apesar de apresentar o sinal negativo com o rating, conforme o esperado, em todos os modelos com os diferentes de tipos de $B T D$, salienta-se que é significativo apenas quando testadas as BTDTAS (coef. - 2,616) e BTDNAS (coef. - 2,003), ambas no quintil alto do setor. O sinal negativo do coeficiente é consoante com estudos prévios (Crabtree \& Maher, 2009; Ayers et al., 2010; Murcia, 2013; Dafydd \& Jong-Seo, 2016). As dívidas de uma empresa podem ser interpretadas como uma medida de risco e, portanto, quanto maior o endividamento de uma empresa, piores tendem a ser as notas de rating (Bouzouita \& Young, 1998; Murcia, 2013). As variáveis ROA e CRE são as únicas não significativas para explicar o rating quando testadas qualquer tipo de $B T D$ no quintil alto do setor (Tabela 7), o que contraria os estudos prévios que mostram que a rentabilidade pode ser um fator determinante do rating (Crabtree \& Maher, 2009; Ayers et al., 2010; Murcia, 2013; Dafydd \& Jong-Seo, 2016) e do crescimento (CRE) das empresas (Murcia, 2013; Dafydd \& JongSeo, 2016).

O FCO apresenta coeficiente positivo e significativo para explicar o rating no modelo do quintil alto da BTDTPOAS (coef. 4,886), BTDNAS (coef. 5,131) e BTDTEAS (coef. 3,943). Isso significa que "empresas com alto fluxo de caixa têm classificações mais altas por causa do menor risco de falência" (Demirtas \& Cornaggia, 2013, p. 139). Já o nível de tangibilidade, apesar de apresentar coeficiente positivo (conforme o esperado) em todos os modelos do quintil alto, é significativo apenas quando são testadas a BTDTNEAS (coef. 1,060), BTDANAS (coef. 0,905) e a BTDPEAS (coef. 1,056). Esse achado vai de encontro aos argumentos de Soares et al. (2012), os quais consideram que o ativo imobilizado pode servir como garantia nos contratos de dívidas e, por isso, quanto maior o nível de tangibilidade das empresas, melhores tendem a ser as notas ratings.

$\mathrm{O}$ potencial de inadimplência dos clientes (PI), diferentemente do esperado, apresentou relação positiva com o rating nos modelos em que se testa a BTDTNEAS (coef. 7,196), BTDANAS (coef. 5,371) e a BTDPEAS (coef. 5,502), estando todas no quintil alto do setor. Esse achado contraria os argumentos de que o nível de inadimplência dos clientes pode demonstrar relação negativa com o rating, uma vez que, quanto maior o nível de inadimplência, maior tende a ser o risco de crédito da empresa, pois afeta negativamente o fluxo de caixa e a capacidade de pagamento das dívidas (Lima et al., 2018).

Conforme previsto em literatura prévia, a independência financeira (IFIN) da empresa apresenta uma relação positiva e significativa com o rating, quando os testes são realizados com a BTDANAS (coef. 2,087992) e a BTDPEAS (coef. 2,329), encontrando-se ambas no quintil alto do setor. Isso indica que, quanto maior o nível de independência financeira da empresa, menor tende a ser o nível de dívidas onerosas. Portanto, menor será o custo de captação de recursos, o que pode reduzir o risco financeiro e, em consequência, melhorar as notas de rating (Gomes Neto, 2017). A margem EBIT (ME) também apresenta uma relação positiva e significativa com o rating quando os testes são realizados com a BTDANAS (coef. 3,448) e a BTDPEAS (coef. 4,780), estando ambas no quintil alto do setor. Esse achado demonstra que, quanto maior a margem EBIT, mais a empresa apresenta facilidade para honrar com seus compromissos financeiros, despesas com imposto de renda e participações dos acionistas, o que facilita a obtenção de notas melhores de rating (Soares et al., 2012).

$\mathrm{Na}$ Tabela 8 encontram-se os resultados para cada uma das BTDs no quintil baixo do setor, considerando o rating em escala ordinal ( 1 a 22). Conforme o esperado, o rating tem relação positiva e significativa com a BTDTNEBS (coef. 130,835) e com a BTDPEBS (coef. 39,530), concentradas no 
quintil baixo do setor. A BTD negativa no quintil baixo do setor significa que o lucro tributável é maior que o lucro contábil, porém, com uma pequena distância. Assim, esse achado não confirma a ideia de Crabtree e Maher (2009), de que deve haver um equilíbrio razoável (nem uma distância grande e nem pequena) entre o lucro contábil e o tributável. Nesse caso, se as empresas divulgarem níveis elevados ou muito baixos de $B T D$, pode indicar inconsistência, o que culminaria em perda de confiança quanto às informações contábeis. Os argumentos de Crabtree e Maher (2009) são de que níveis baixos de BTDTNEBS (lucro contábil próximo do lucro tributável) podem indicar falta de planejamento tributário e, nesse caso, o lucro contábil pode se tornar ainda menor nos anos futuros. Contudo, a relação positiva documentada sugere que as agências de rating não penalizam as empresas que divulgam $B T D$ negativa no quintil baixo do setor.

Tabela 8 - Regressão logística ordenada - rating em escala ordinal e BTD no quintil baixo do setor

\begin{tabular}{|c|c|c|c|c|c|c|c|c|c|}
\hline \multicolumn{10}{|c|}{ 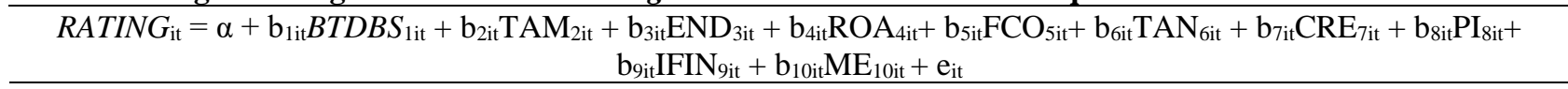 } \\
\hline $\begin{array}{c}\text { Variáveis } \\
\text { Explicativas }\end{array}$ & $\begin{array}{c}\text { Sinal } \\
\text { Previsto }\end{array}$ & & BTDT & ВТDTРО & BTDTNE & $B T D A N$ & BTDN & BTDPE & BTDTE \\
\hline \multirow{2}{*}{$B T D B S$} & & beta & 2,152 & $-10,633$ & 130,835 & 0,649 & 8,707 & 39,530 & $-3,091$ \\
\hline & $+\mathrm{ou}-$ & $\mathrm{p}$-valor & 0,904 & 0,785 & 0,004 & 0,970 & 0,555 & 0,054 & 0,930 \\
\hline \multirow{2}{*}{ TAM } & \multirow{2}{*}{+} & beta & 0,518 & 0,506 & 0,646 & 0,607 & 0,596 & 0,462 & 0,601 \\
\hline & & $\mathrm{p}$-valor & 0,000 & 0,000 & 0,000 & 0,000 & 0,000 & $\mathbf{0 , 0 0 0}$ & 0,000 \\
\hline \multirow{2}{*}{ END } & \multirow[b]{2}{*}{+} & beta & $-1,457$ & $-0,555$ & $-2,963$ & $-1,456$ & 0,332 & $-0,406$ & $-2,445$ \\
\hline & & $\mathrm{p}$-valor & 0,061 & 0,576 & 0,028 & 0,600 & 0,689 & 0,587 & 0,004 \\
\hline \multirow{2}{*}{ ROA } & \multirow{2}{*}{+} & beta & $-3,552$ & $-3,434$ & $-5,927$ & 2,292 & 0,251 & $-2,862$ & $-0,580$ \\
\hline & & $\mathrm{p}$-valor & 0,217 & 0,370 & 0,210 & 0,384 & 0,922 & 0,284 & 0,803 \\
\hline \multirow{2}{*}{$\mathrm{FCO}$} & \multirow{2}{*}{+} & beta & 1,230 & 0,032 & 3,899 & $-1,372$ & $-1,460$ & 2,907 & 0,204 \\
\hline & & $\mathrm{p}$-valor & 0,587 & 0,992 & 0,300 & 0,589 & 0,537 & 0,219 & 0,922 \\
\hline \multirow{2}{*}{ TAN } & \multirow{2}{*}{+ ou - } & beta & 0,135 & 0,252 & 0,113 & 0,144 & 0,848 & 0,266 & 0,533 \\
\hline & & $\mathrm{p}$-valor & 0,632 & 0,491 & 0,783 & 0,609 & 0,001 & 0,332 & 0,047 \\
\hline \multirow{2}{*}{ CRE } & \multirow[b]{2}{*}{+} & beta & $-0,566$ & 0,323 & $-0,242$ & $-0,366$ & 0,221 & $-0,779$ & $-0,594$ \\
\hline & & $\mathrm{p}$-valor & 0,475 & 0,736 & 0,858 & 0,631 & 0,786 & 0,286 & 0,424 \\
\hline \multirow{2}{*}{ PI } & \multirow[b]{2}{*}{ - } & beta & 1,546 & 3,133 & $-0,128$ & 0,295 & 1,226 & 1,079 & 1,300 \\
\hline & & $\mathrm{p}$-valor & 0,295 & 0,094 & 0,963 & 0,848 & 0,384 & 0,426 & 0,372 \\
\hline \multirow{2}{*}{ IFIN } & \multirow{2}{*}{+} & beta & 1,972 & 2,124 & 1,842 & 1,794 & 1,736 & 1,307 & 1,146 \\
\hline & & $\mathrm{p}$-valor & 0,014 & 0,046 & 0,173 & 0,034 & 0,047 & 0,109 & 0,159 \\
\hline \multirow{2}{*}{ ME } & \multirow{2}{*}{+} & beta & $-1,911$ & $-4,253$ & 1,435 & 0,747 & 1,150 & $-0,685$ & 3,221 \\
\hline & & p-valor & 0,377 & 0,111 & 0,683 & 0,692 & 0,668 & 0,714 & 0,105 \\
\hline Likelihood Ratio & & & $-789,466$ & $-538,388$ & $-277,453$ & $-882,388$ & $-835,186$ & $-865,678$ & 832,510 \\
\hline Prob $>$ F & & & 0,000 & 0,000 & 0,000 & 0,000 & 0,000 & 0,000 & 0,000 \\
\hline Pseudo R2 & & & 0,049 & 0,047 & 0,074 & 0,046 & 0,056 & 0,040 & 0,05 \\
\hline Número observaç & & & 324 & 220 & 117 & 355 & 345 & 354 & 33 \\
\hline
\end{tabular}

Nota: $R A T I N G$ é o rating em escala ordinal de 1 a $22 . B T D T$ é a $B T D$ total no quintil alto do setor. BTDTPO é a $B T D$ total positiva no quintil alto do setor. $B T D T N E$ é a $B T D$ total negativa no quintil alto do setor. BTDAN é a $B T D$ anormal no quintil alto do setor. $B T D N$ é a $B T D$ normal no quintil alto do setor. $B T D P E$ é a $B T D$ permanente no quintil alto do setor. BTDTE é a BTD temporária no quintil alto do setor. TAM: logaritmo natural do ativo total; END: dividas totais dividida pelo ativo total; ROA: lucro operacional dividido pelo ativo total no ano t, FCO: fluxo de caixa operacional divido pelo ativo total; TAN: imobilizado no ano t dividido pelo $A T$ defasado em $t-1$; $C R E$ variação das vendas entre os anos $t$ e $t$ - 1 , dividido pelas vendas no ano $t-1$; PI provisão de créditos de liquidação duvidosa dividido por clientes; IFIN: patrimônio líquido divido pelo ativo total no ano t; ME: EBIT dividido pela receita líquida.

Fonte: dados da pesquisa.

Por outro lado, é possível justificar a relação positiva e significativa entre BTDTNE no quintil baixo do setor e rating, pois o fato de a BTDTNE estar no quintil baixo do setor (lucro tributável é maior que o lucro contábil, porém, com uma pequena distância) pode indicar que a empresa não está engajada em gerenciamento de resultado tributável agressivo, visto que, se estivesse, poderia chamar a atenção do fisco, gerar pagamento de multas e, assim, comprometer o caixa futuro da empresa (Crabtree \& Maher, 2009). No que se refere à BTD permanente, a relação positiva encontrada com o 
rating sugere, conforme o previsto, que baixos valores de $B T D$ permanente acabam gerando um efeito positivo sobre as notas de rating, ao não apontar que a empresa está envolvida com atividades de evasão fiscal.

Em relação às demais variáveis de controle, semelhante ao ocorrido nos achados do quintil alto (Tabela 7), verifica-se (Tabela 8) que a única variável significativa em todos os modelos (com os diferentes tipos de BTD no quintil baixo do setor) para explicar o rating é o tamanho da empresa, o qual apresenta relação positiva e significativa ao nível de $1 \%$. Novamente, isso confirma que as empresas maiores apresentam menor risco, maior facilidade ao crédito e, portanto, obtêm ratings melhores (Bouzouita \& Young, 1998; Kim \& Gu, 2004, Murcia, 2013).

Já o endividamento é significativo apenas quando testada a BTDT (coef. -1,457), a BTDTNE (coef. -2,963) e a BTDTE (coef. -2,445). A diferença é que, no quintil alto do setor, o resultado não é significativo para o modelo com a BTDTNE e a BTDTE, apenas para a BTDN. Contudo, esse fato indica que as dívidas de uma empresa podem ser interpretadas como uma medida de risco e, portanto, quanto maior o endividamento de uma empresa, piores tendem a ser as notas de rating (Bouzouita \& Young, 1998; Murcia, 2013). Novamente, as variáveis ROA e CRE não são significativas para explicar o rating quando testado qualquer tipo de BTD no quintil baixo do setor (Tabela 8). Além disso, o FCO e o ME também não são significativos nos testes com a $B T D$ no quintil baixo do setor.

O nível de tangibilidade, apesar de apresentar coeficiente positivo (conforme o esperado) em todos os modelos do quintil baixo, é significativo apenas quando são testadas a BTDTN (coef. 0,848) e a BTDTE (coef. 0,534). Esse achado se destoa um pouco do que foi encontrado no quintil alto, porém, confirma que o ativo imobilizado pode servir como garantia nos contratos de dívidas e, por isso, quanto maior o nível de tangibilidade das empresas, melhores tendem ser as notas ratings (Soares et al., 2012). O potencial de inadimplência dos clientes (PI), diferentemente do esperado, apresenta relação positiva com o rating apenas nos modelos em que se testa a BTDTPO no quintil baixo (coef. 3,133 ), visto que, no quintil alto, há significância quando se testam a BTDTNE, a BTDAN e a $B T D P E$ (coef. 5,501). Novamente, esse achado contraria os argumentos de que o nível de inadimplência dos clientes pode demonstrar relação negativa com o rating, uma vez que, quanto maior o nível de inadimplência, maior tende a ser o risco de crédito da empresa, pois afeta negativamente o fluxo de caixa e a capacidade de pagamento das dívidas (Lima et al., 2018).

Conforme previsto por Gomes Neto (2017), a independência financeira (IFIN) da empresa apresenta uma relação positiva e significativa com o rating, quando os testes são realizados com a BTDT (coef. 1,972), a BTDTPO (coef. 2,124), a BTDAN (coef. 1,794) e a BTDN (coef. 1,734), encontrando-se todas no quintil baixo do setor. Esses achados demonstram que, devido ao maior nível de independência financeira da empresa, menor tende a ser o nível de dívidas onerosas e, portanto, menor o custo de captação de recursos. Assim, menor é o risco financeiro e melhores são as notas de rating (Gomes Neto, 2017).

\subsection{Análise adicional}

Como teste adicional, em busca de verificar a robustez e sensibilidade dos resultados, o modelo especificado na Equação 1 foi também testado com uma variável dummy para o rating (conforme especificado na Tabela 3), tendo o valor 1 para empresas com classificações no Grau Especulativo e 0, para as empresas com rating no Grau de Investimento (Sibim, 2017). Seguindo o mesmo raciocínio da hipótese estabelecida no referencial teórico, porém, por se tratar agora do rating em situação desfavorável (no grau especulativo), o sinal esperado inverte-se. Ou seja, antes esperavase uma associação negativa entre rating e $B T D$, agora pressupõe-se uma associação positiva.

Os resultados em que a $B T D$ é testada no quintil alto do setor demonstram que a BTDTAS (coef. 3,534; p 0,049), a BTDANAS (coef. 3,240) e a BTDNAS (coef. 28,162) têm relação positiva e significativa com o rating no grau especulativo. Esse resultado é esperado, pois demonstra que, quanto mais distante a $B T D$ está da média do setor, mais fácil é obter uma nota de rating no grau especulativo. Esse achado confirma as evidências de Crabtree e Maher (2009), de que os analistas de 
rating penalizam empresas com grandes valores de $B T D$, ou seja, bem acima da média do setor. Além disso, esse resultado demonstra que as agências de rating penalizam as empresas com BTD anormal no quintil alto do setor. Além disso, quando a empresa apresenta elevados níveis de BTD normal, gera um sinal de alerta, que indica que os gestores poderiam ter se aproveitado oportunisticamente e gerenciado o lucro contábil e/ou tributável.

Os resultados em que a $B T D$ é testada no quintil baixo do setor demonstram que a BTDTNEBS (coef. -121,052) e a BTDPEBS (coef. -50,077) têm relação negativa e significativa com o rating no grau especulativo. Esse resultado ocorre conforme o esperado, pois demonstra que, quando a $B T D$ está no quintil baixo do setor, menor é a probabilidade de se obter uma nota de rating no grau especulativo. Esse achado é condizente com o resultado encontrado quando testado o rating em escala ordinal e a $B T D$ no quintil baixo do setor. Tais achados confirmam que, de fato, empresas que mantêm a BTDTNE e a BTDPE no quintil baixo do setor, ou seja, próximo de zero (longe da média do setor), não são penalizadas pelos analistas de rating. Na visão das agências de rating, parece ser algo bom manter a BTDTNE e a BTDPE no quintil baixo do setor.

Isso faz sentido, pois entende-se que baixos níveis de BTDTNE (lucro contábil próximo do lucro tributável) podem indicar que a empresa não está engajada em gerenciamento tributário agressivo. Isso pode ser visto como algo positivo, pois tais empresas não correm o risco de ser penalizadas pelo fisco e receberem multas, que gerariam impactos negativos no caixa em momentos futuros. A respeito da BTDPEBS, pode-se interpretar que, quando ela está concentrada no quintil baixo do setor, é como um sinal de que a empresa não está engajada em atividades agressivas de gerenciamento tributário. Assim, geram um efeito positivo no rating.

$\mathrm{Na}$ Tabela 9 consta o resumo dos resultados da regressão com o rating em escala ordinal (seção 4.2) e dummy (seção 4.3).

Tabela 9 - Resumo dos resultados da regressão

\begin{tabular}{|c|c|c|}
\hline \multirow{2}{*}{ Variáveis de Interesse } & \multicolumn{2}{|c|}{ RATING } \\
\hline & Escala Ordinal & Dummy \\
\hline \multicolumn{3}{|l|}{ BTD quintil alto do setor } \\
\hline BTDTAS & - & + \\
\hline BTDTPOAS & + & NSIG \\
\hline BTDTNEAS & NSIG & NSIG \\
\hline BTDANAS & - & + \\
\hline$B T D N A S$ & - & + \\
\hline BTDPEAS & - & NSIG \\
\hline BTDTEAS & NSIG & NSIG \\
\hline \multicolumn{3}{|l|}{ BTD quintil baixo do setor } \\
\hline BTDTBS & NSIG & NSIG \\
\hline BTDTPOBS & NSIG & NSIG \\
\hline BTDTNEBS & + & - \\
\hline$B T D A N B S$ & NSIG & NSIG \\
\hline$B T D N B S$ & NSIG & NSIG \\
\hline BTDPEBS & + & - \\
\hline BTDTEBS & NSIG & NSIG \\
\hline
\end{tabular}

Nota: NSIG denota que não houve significância estatística. Os sinais + e - significam relação positiva e negativa entre a BTD e o RATING, respetivamente. BTDTAS é a BTD total no quintil alto do setor. BTDTPOAS é a BTD total positiva no quintil alto do setor. BTDTNEAS é a BTD total negativa no quintil alto do setor. BTDANAS é a BTD anormal no quintil alto do setor. BTDNAS é a $B T D$ normal no quintil alto do setor. BTDPEAS é a $B T D$ permanente no quintil alto do setor. $B T D T E A S$ é a $B T D$ temporária no quintil alto do setor. BTDTBS é a $B T D$ total no quintil baixo do setor. BTDTPOBS é a $B T D$ total positiva no quintil baixo do setor. $B T D T N E B S$ é a $B T D$ total negativa no quintil baixo do setor. $B T D A N B S$ é a $B T D$ anormal no quintil baixo do setor. $B T D N B S$ é a $B T D$ normal no quintil baixo do setor. BTDPEBS é a $B T D$ permanente no quintil baixo do setor. BTDTEBS é a $B T D$ temporária no quintil baixo do setor.

Fonte: dados da pesquisa.

Os resultados são robustos quando se testa a $B T D$ no quintil baixo do setor, em que não faz diferença se o rating está em escala numérica ordinal ou como variável dummy (grau especulativo e 
de investimento). Já os resultados com a $B T D$ no quintil alto do setor mostram robustez para a BTDTAS, BTDTNEAS, BTDANS, BTDNAS e BTDTEAS, cujos resultados também são semelhantes, independente de testar o rating em escala ordinal ou dummy. Porém, os testes com a BTDTPOAS $e$ BTDPEAS se divergem quando a variável rating muda de escala ordinal para dummy, sendo o resultado da regressão significativa apenas no primeiro caso. Assim, a análise adicional realizada no presente estudo permite verificar uma sensibilidade entre a relação da BTDTPOAS e BTDPEAS com o rating quando se altera o formato da mensuração deste último. A partir disso, pode-se sugerir que a BTDTPOAS tem a capacidade de gerar notas de rating maiores, porém, não garante que o rating obtido pelas empresas seja classificado no grau de investimento. No que se refere à BTDPEAS, ocorre o contrário, o fato das empresas apresentarem esse tipo de BTD tende a favorecer notas de rating menores, mas sem significar que o rating caia no grau especulativo.

No quintil baixo do setor é possível observar que apenas as $B T D$ negativa e permanente são significativas, enquanto no quintil alto apenas as $B T D$ negativa e temporária não são significativas para explicar o rating. Isso demonstra que o foco e/ou preocupação principal das agências de rating se concentra nos valores da $B T D$ que estão no quintil alto do setor. Talvez isso ocorra, porque quanto maior a distância entre as duas medidas de lucro, maiores são as chances de as empresas estarem envolvidas com atividades agressivas de gerenciamento, tanto do lucro contábil quanto do tributável (Crabtree \& Maher, 2009), uma vez que os gestores são incentivados a maximizar o lucro contábil e reduzir o lucro tributável (Ferreira et al., 2012).

Além disso, a divergência entre os resultados no que se refere aos diferentes tipos de BTD pode sugerir que um tipo de BTD é mais relevante que o outro para explicar as notas de rating, pois nem todos os tipos podem ser considerados pelas agências de rating em suas avaliações de risco. Mas também demonstra que a $B T D$ pode ser uma medida complexa para explicar o rating, uma vez que não há um padrão entre os reflexos dos tipos de $B T D$ no rating.

Os achados da presente pesquisa corroboram aqueles dos estudos de Alissa et al. (2013), Kim et al. (2013), Demirtas e Cornaggia (2013), Brown et al. (2015), Dafydd e Jong-seo (2016) e Sibim (2017), os quais argumentam que os gestores são incentivados a se engajar em atividades de gerenciamento de resultados como forma de influenciar a emissão das notas de rating por parte das agências. No entanto, os achados de Dafydd e Jong-seo (2016) demonstraram que nem sempre o gerenciamento de resultados poderá gerar um efeito positivo sobre as notas de rating. Pelo contrário, as empresas que participam do gerenciamento de resultados têm mais probabilidade de sofrerem uma redução no rating. Os resultados de Miiller e Martinez (2016) também sugerem que um aumento no gerenciamento de resultados gera notas de rating menores. Assim, os achados da presente pesquisa, ao demonstrar que níveis maiores de $B T D$ aumentam a chance de as empresas terem notas de rating menores; e ao considerar que parte da $B T D$ resulta das ações discricionárias dos gestores (Chan et al., 2010); permitem inferir que as ações dos gestores voltadas ao gerenciamento de resultados não tendem a gerar efeito positivo sobre as avaliações de crédito das agências de rating. Tal achado também sinaliza aos gestores um alerta quanto aos incentivos para o gerenciamento de resultados, já que este reflete nos valores da $B T D$ que, por sua vez, podem impactar negativamente as notas de rating. Portanto, é indicado que tenham cautela antes de se engajar em atividades agressivas que interfiram discricionariamente nos valores das duas medidas de lucro (Contábil e Tributável).

Os resultados da relação entre rating e BTD confirmam que as evidências de Crabtree e Maher (2009) e Ayers et al. (2010) são concretas. Portanto, a BTD tem conteúdo informacional útil às agências de rating em suas avaliações de risco de crédito. Os achados demonstram que há relevância em segregar as $B T D$ em seus diferentes tipos e classificá-las em quintil alto e baixo do setor, pois a associação com o rating pode ser diferente.

Os resultados da presente pesquisa são compreendidos a partir da Teoria Contratual da Firma, especificamente, no ponto em que as agências de rating representam um dos intermediários da informação contábil, agindo como monitores da gestão das empresas em relação aos números contábeis que são divulgados. As agências de rating assumem um importante papel para garantir a 
eficiência dos contratos que são estabelecidos entre empresa e stakeholders. Alinhado a isso, tem-se os pressupostos da Teoria da Sinalização, de que os agentes de mercado interpretam as informações disponíveis em ambiente de assimetria (Spence, 1973). Assim, é possível sugerir que a BTD seja vista pelas agências de rating como uma variável capaz de sinalizar a qualidade dos números contábeis.

Tendo em vista que parte da BTD pode ser decorrente do gerenciamento de resultados, decorrente das ações discricionárias dos gestores (Chan et al., 2010), é possível afirmar que, em busca de obter ratings melhores, os gestores podem manipular discricionariamente os valores que interferem na $B T D$. Porém, as evidências da presente pesquisa demonstram que essa manipulação pode gerar consequências negativas para as empresas. Os resultados da pesquisa, portanto, corroboram a sugestão de Fields et al. (2001) quanto à relevância de se investigar se a gestão da divulgação financeira é bem sucedida e quais são os reflexos das escolhas contábeis.

\section{CONSIDERAÇÕES FINAIS}

O objetivo desta pesquisa consistiu em verificar a associação entre os diferentes tipos de BTD e as notas de rating. Os principais resultados são: a) o rating tem relação negativa e significativa com as BTD's total, normal, anormal e permanente no quintil alto do setor, demonstrando que os analistas de rating penalizam empresas com grandes valores de $B T D ; b) \mathrm{O}$ rating tem relação positiva e significativa com a BTD positiva no quintil alto do setor, demonstrando que, quanto maior o lucro contábil em relação ao tributável, melhores tendem a ser as notas de rating das empresas; c) O rating tem relação positiva e significativa com as BTD's negativa e permanente no quintil baixo do setor, demonstrando que o fato das empresas divulgarem a $B T D$ nesse nível favorece a uma nota de rating melhor; d) Os resultados são robustos quando se testa a BTD no quintil baixo do setor, em que não faz diferença se o rating está em escala numérica ordinal ou como variável dummy (grau especulativo e de investimento); e) Os resultados são robustos quando se testa as BTD’s total, negativa, normal, anormal e temporária no quintil alto do setor $e$ o rating em escala ordinal ou dummy, não apresentando diferença nos resultados; f) Os testes com as BTD’s positiva e permanente no quintil alto do setor se divergem quando a variável rating muda de escala ordinal para dummy, demonstrando sensibilidade entre a relação dessas variáveis com o rating quando se altera o formato do rating.

Diante dos resultados apresentados, as principais conclusões são: a) as empresas que mantêm uma distância pequena entre o lucro contábil e o tributável tendem a receber melhores avaliações das agências de rating, ou seja, são os elevados níveis de $B T D$ que impactam negativamente nas notas de rating; b) as agências de rating penalizam as empresas que mantêm números elevados de $B T D$, oferecendo avaliações de rating mais baixas, enquanto menores distâncias entre o lucro contábil e o tributável não parecem ser motivo de preocupação por parte delas; c) a segregação da BTD nos diferentes tipos e quintis é relevante por apresentar resultados divergentes; d) A divergência entre os resultados no que se refere aos diferentes tipos de BTD pode sugerir que um tipo de $B T D$ é mais relevante que o outro para explicar as notas de rating, pois sugerem que nem todos os tipos de $B T D$ são avaliados pelas agências de rating em suas avaliações de risco. Isso implica que a BTD pode ser uma medida complexa para explicar o rating, uma vez que não há um padrão entre os reflexos dos tipos de BTD no rating.

Uma das principais contribuições da presente pesquisa é corroborar as afirmações de Crabtree e Maher (2009) e Ayers et al. (2010), de que a BTD têm conteúdo informacional útil às agências de rating em suas avaliações de risco de crédito. Além disso, contribui-se com a literatura, ao fornecer detalhes sobre a associação entre os diferentes tipos de $B T D$ e o rating, evidenciando quais são os tipos de $B T D$ que podem impactar nas avaliações das agências de rating. Os resultados ainda podem ser úteis aos gestores, no sentido de alertá-los de que é preciso ter precaução quanto à divulgação dos números que envolvem os diferentes tipos de $B T D$, uma vez que poderá ter consequências econômicas relacionadas ao rating. Investidores e outros usuários da informação contábil poderão se beneficiar também utilizando a BTD para avaliar a qualidade dos números contábeis. Diante do conhecimento 
sobre a relação entre $B T D$ e rating, poderão demonstrar insatisfação ou descontentamento sobre a qualidade com que o lucro contábil e o tributável estejam sendo apurados pelas empresas.

Os achados da presente pesquisa são compreendidos a partir da Teoria Contratual da Firma, especificamente, no ponto em que as agências de rating representam um dos intermediários da informação contábil, agindo como monitores da gestão das empresas em relação aos números contábeis que são divulgados. As agências de rating assumem um importante papel para garantir a eficiência dos contratos que são estabelecidos entre empresa e stakeholders. Alinhado a isso, tem-se os pressupostos da Teoria da Sinalização, de que os agentes de mercado interpretam as informações disponíveis em ambiente de assimetria (Spence, 1973). Assim, os resultados desta pesquisa sugerem que a $B T D$ pode ser vista pelas agências de rating como uma variável capaz de sinalizar a qualidade dos números contábeis.

Destaca-se que como limitações da pesquisa a não realização dos testes separadamente entre os países da amostra, para verificar se há diferenças significativas entre os resultados. Ressalta-se que isso não foi possível em virtude de uma outra limitação da pesquisa, que é a amostra pequena, ou seja, os critérios amostrais resultaram em poucas observações por país, o que não permitiria realizar a análise separadamente. Outra limitação se refere ao próprio cálculo da $B T D$, para o qual foi utilizado o lucro tributável, uma informação não disponível nos relatórios contábeis e/ou base de dados. Assim, o lucro tributável utilizado para o cálculo da $B T D$ é uma aproximação.

Entre as lacunas ainda identificadas sobre o tema abordado e que podem gerar estudos futuros, cita-se: a) estudar diversos países individualmente, observando as características institucionais; b) controlar os títulos de emissão de dívidas que possuem garantias reais, o que pode interferir nos resultados, já que os credores terão uma garantia sobre o crédito estabelecido nos contratos. Assim, os incentivos dos gestores ao gerenciamento de resultados para interferir nos valores da $B T D$ podem ser menores; e c) verificar se empresas com maior nível de gerenciamento de resultados apresentam uma relação diferente entre rating e $B T D$.

\section{REFERÊNCIAS}

Adams, M., Burton, B., \& Hardwick, P. (2003). The determinants of credit ratings in the United Kingdom insurance industry. Journal of Business Finance \& Accounting, 30(3-4), 539-572. Doi: https://doi.org/10.1111/1468-5957.00007.

Alissa, W., Bonsall Iv, S. B., Koharki, K., \& Penn Jr, M. W. (2013). Firms' use of accounting discretion to influence their credit ratings. Journal of Accounting and Economics, 55(2-3), 129-147. Doi: http://dx.doi.org/10.1016/j.jacceco.2013.01.001.

Alves, P. F. P., \& Ferreira, M. A. (2011). Capital structure and law around the world. Journal of Multinational Financial Management, 21(3), 119-150. Doi: 10.1016/j.mulfin.2011.02.001.

Ayers, B. C., Laplante, S. K., \& McGuire, S. T. (2010). Credit ratings and taxes: The effect of book-tax differences on ratings changes. Contemporary Accounting Research, 27(2), 359-402. Doi: https://doi.org/10.1111/j.1911-3846.2010.01011.x.

Badertscher, B. A., Phillips, J. D., Pincus, M., \& Rego, S. O. (2009). Earnings management strategies and the trade-off between tax benefits and detection risk: To conform or not to conform?. The Accounting Review, 84(1), 63-97. Doi: 10.2308/accr.2009.84.1.63.

Blaylock, B., Gaertner, F. B., \& Shevlin, T. (2017). Book-tax conformity and capital structure. Review of Accounting Studies, 22(2), 903-932. Doi: 10.1007/s11142-017-9386-2.

Bis, C., \& Martinez, A. L. (2017). Agressividade fiscal em empresas brasileiras com controle de capital estrangeiro. Anais da EnANPAD. São Paulo, SP, Brasil, 41. Doi: n/d.

Blume, M. E., Lim, F., \& MacKinlay, A. C. (1998). The declining credit quality of US corporate debt: Myth or reality?. The Journal of Finance, 53(4), 1389-1413. Doi: n/d.

Bouzouita, R., \& Young, A. J. (1998). A probit analysis of best ratings. Journal of Insurance Issues, 23-34. Doi: $\mathrm{n} / \mathrm{d}$.

Brown, K., Chen, V. Y., \& Kim, M. (2015). Earnings management through real activities choices of firms near the investment-speculative grade borderline. Journal of Accounting and Public Policy, 34(1), 7494. Doi: http://dx.doi.org/10.1016/j.jaccpubpol.2014.09.002. 
Chan, K. H., Lin, K. Z., \& Mo, P. L. (2010). Will a departure from tax-based accounting encourage tax noncompliance? Archival evidence from a transition economy. Journal of Accounting and Economics, 50(1), 58-73. Doi: http://dx.doi.org/10.1016/j.jacceco.2010.02.001.

Comprix, J., Graham, R. C., \& Moore, J. A. (2011). Empirical evidence on the impact of book-tax differences on divergence of opinion among investors. Journal of the American Taxation Association, 33(1), 51-78. Doi: https://doi.org/10.2308/jata.2011.33.1.51.

Costa, P. S., Lopes, A. B. (2015). Implicações da adoção das IFRS sobre as book-tax differences: O caso do Brasil. 1. ed. Alemanhã: Novas Edições Acadêmicas.

Crabtree, A., \& Maher, J. J. (2009). The influence of differences in taxable income and book income on the bond credit market. Journal of the American Taxation Association, 31(1), 75-99. Doi: https://doi.org/10.2308/jata.2009.31.1.75.

Damasceno, D. L.; Artes, R., \& Minardi, A. M. A. (2008). Determinação de rating de crédito de empresas brasileiras com a utilização de índices contábeis. Revista da Administração, v. 43, n. 4, p. 344-355, Outubro/Novembro/Dezembro. Doi: $\mathrm{n} / \mathrm{d}$.

Dantas, J. A., Paulo, E., \& Medeiros, O. R. (2013). Conditional conservatism in the Brazilian banking industry in situations of higher risk perception. Revista Universo Contábil, 9(2), 83-103, 2013. Doi: https://dx.doi.org/10.4270/ruc.2013214.

Dafydd, M., \& Jong-Seo, C. (2016). Does earnings management influence credit rating changes in subsequent periods?: An analysis of KRX firms. Korea International Accounting Review, 2016(67), 122. Doi: http://dx.doi.org/10.21073/kiar/2016..67.001.

Demirtas, K. O., \& Cornaggia, K. R. (2013). Initial credit ratings and earnings management. Review of Financial Economics, 22(4), 135-145. Doi: http://dx.doi.org/10.1016/j.rfe.2013.05.003.

Edwards, A., Schwab, C., \& Shevlin, T. (2016). Financial constraints and cash tax savings. The Accounting Review, 91(3), 859-881. Doi: 10.2308/accr-51282.

Fávero, L. P., \& Belfiore, P. (2017). Manual de análise de dados: estatística e modelagem multivariada com Excel®, SPSS® e Stata®. Elsevier Brasil.

Ferreira, F. R., Martinez, A. L., Costa, F. M. D., \& Passamani, R. R. (2012). Book-tax differences e gerenciamento de resultados no mercado de ações do Brasil. Revista de Administração de Empresas, 52(5), 488-501. Doi: http://dx.doi.org/10.1590/S0034-75902012000500002.

Fields, T. D., Lys, T. Z., \& Vincent, L. (2001). Empirical research on accounting choice. Journal of Accounting and Economics, 31(1-3), 255-307. Doi: https://doi.org/10.1016/S0165-4101(01)00028-3.

Fonseca, K. B. C., \& Costa, P. S. (2017). Fatores determinantes das book-tax differences. Revista de Contabilidade e Organizações, 11(29), 17-29. Doi: http://dx.doi.org/10.11606/rco.v11i29.122331.

Francis, J., Huang, A. H., Rajgopal, S., \& Zang, A. Y. (2008). CEO reputation and earnings quality. Contemporary Accounting Research, 25(1), 109-147.

Frank, M. M., Lynch, L. J., \& Rego, S. O. (2009). Tax reporting aggressiveness and its relation to aggressive financial reporting. The Accounting Review, 84(2), 467-496. Doi: http://dx.doi.org/10.2139/ssrn.647604.

Gomes Neto, J. T (2017). Determinantes do rating de instituições financeiras: Uma análise em países emergentes e não emergentes, 2017, 105 f. Dissertação (Mestrado em Ciências Contábeis) - Programa de Pós-Graduação em Ciências Contábeis da UnB.

Graham, J. R., \& Harvey, C. R. (2001). The theory and practice of corporate finance: Evidence from the field. Journal of Financial Economics, 60(2-3), 187-243. Doi: https://doi.org/10.1016/S0304405X(01)00044-7.

Graham, J. R., Harvey, C. R., \& Rajgopal, S. (2005). The economic implications of corporate financial reporting. Journal of Accounting and Economics, 40(1-3), 3-73. Doi: https://doi.org/10.1016/j.jacceco.2005.01.002.

Gray, S., Mirkovic, A., \& Ragunathan, V. (2006). The determinants of credit ratings: Australian evidence. Australian Journal of Management, 31(2), 333-354. Doi: https://doi.org/10.1177/031289620603100208.

Hanlon, M. (2005). The persistence and pricing of earnings, accruals, and cash flows when firms have large book-tax differences. The Accounting Review, 80(1), 137-166. Doi: https://doi.org/10.2308/accr.2005.80.1.137. 
Healy, P. M., \& Palepu, K. G. (2001). Information asymmetry, corporate disclosure, and the capital markets: A review of the empirical disclosure literature. Journal of Accounting and Economics, 31(1-3), 405440.

Kim, H., \& Gu, Z. (2004). Financial determinants of corporate bond ratings: an examination of hotel and casino firms. Journal of Hospitality \& Tourism Research, 28(1), 95-108. Doi: https://doi.org/10.1177/1096348003261217.

Kim, Y. S., Kim, Y., \& Song, K. R. (2013). Credit rating changes and earnings management. Asia-Pacific Journal of Financial Studies, 42(1), 109-140. Doi:10.1111/ajfs.12007.

Kisgen, D. J. (2006). Credit ratings and capital structure. The Journal of Finance, 61(3), 1035-1072. Doi: https:// http://doi.org/10.1111/j.1540-6261.2006.00866.x.

Jensen, M. C., \& Meckling, W. H. (1976). Theory of the firm: managerial behavior, agency costs and ownership structure. Journal of Financial Economics, 3(4), 305-360. Doi: https://doi.org/10.1016/0304-405X(76)90026-X.

Zambardi, J. M. R., Lopes, C. T., Morais, S. C. R. V., Newhouse, R. P., Lopes, J. D. L., \& Barros, A. L. B. L. D. (2019). Adaptação transcultural para o Brasil e confiabilidade da Smoking Cessation Counseling. Acta Paulista de Enfermagem, 32(3), 290-297. Doi: http://dx.doi.org/10.1590/1982 7849rac2018160373.

Lima, F. G, Fonseca, C. V. C., Silveira, R. L. F. \& Assaf Neto, A. (2018). Os Determinantes dos Ratings de Crédito dos Bancos Brasileiros. Revista de Administração Contemporânea, v 22. Doi: http://dx.doi.org/10.1590/1982 -7849rac2018160373.

Lopes, A. B.; Martins, E (2005). Teoria da contabilidade: uma nova abordagem. São Paulo: Atlas.

Marques, A. V. C., Costa, P. D. S., \& Silva, P. R. (2016). Relevância do conteúdo informacional das booktax differences para previsão de resultados futuros: evidências de países-membros da América Latina. Revista Contabilidade \& Finanças, 27(70), 29-42. Doi: 10.1590/1808-057x201501570.

Martinez, A. L., \& Passamani, R. R. (2014). Book-tax differences e sua relevância informacional no mercado de capitais no Brasil. Revista de Gestão, Finanças e Contabilidade, 4(2), 20-37. Doi: http://dx.doi.or/10.180828/rgfc.v4i2.615.

Miiller, D. L., \& Martinez, A. L. (2016). Book-tax difference, earnings management and bond ratings in the Brazilian market. Revista Universo Contábil, 12(3), 91-109. Doi: https://doi.org/10.4270/ruc.2016323.

Murcia, F. C. S (2013). Rating de crédito no brasil: Fatores Determinantes e Impacto de Anúncios nos Preços das Ações. 2013, 155 f. Tese (Doutorado em Administração) - Universidade Federal de Santa Catarina.

Plesko, G. A. (1999, January). Book-tax differences and the measurement of corporate income. In Proceedings. Annual Conference on Taxation and Minutes of the Annual Meeting of the National Tax Association (Vol. 92, pp. 171-176). National Tax Association. Doi: n/d.

Santos, C. K. S.; Costa, P. S.; Silva, P. R. (2016). Relação entre book-tax differences e conservadorismo contábil: um estudo das companhias abertas de países da América Latina. Revista Contemporânea de Contabilidade, UFSC, Florianópolis, 13(30), 160-192. Doi: http://dx.doi.org/10.5007/21758069.2016v13n30p160.

Salvador, C., Pastor, J. M., \& de Guevara, J. F. (2014). Impact of the subprime crisis on bank ratings: The effect of the hardening of rating policies and worsening of solvency. Journal of Financial Stability, 11, 13-31. Doi: http://dx.doi.org/10.1016/j.jfs.2013.10.005.

S\&P Global (2016). Ratings. Disponível em: 〈https://www.spglobal.com/ratings/en/index>. Acesso em, 12, 2016.

Sheng, H. H (2005). Ensaios sobre emissões de corporate bonds (debêntures) no mercado brasileiro. Doutorado em administração de empresas, Escola de Administração de Empresas de São Paulo da Fundação Getulio Vargas, São Paulo, SP, Brasil.

Sibim, M. C. (2017) Gerenciamento de resultados e risco de crédito: estudo em companhias que negociam na BM\&FBOVESPA. Dissertação de Mestrado, Universidade Federal do Paraná, Curitiba, PR, Brasil.

Silva, E.S., Santos, J. F., \& Almeida, M. A. (2012). Os efeitos dos mecanismos de governança corporativa sobre os ratings de crédito das debêntures. Revista de Negócios, 17(3), 80-93. Doi: n/d.

Soares, G. D. O. G., Coutinho, E. S., \& de Camargos, M. A. (2012). Determinantes do rating de crédito de companhias brasileiras. Contabilidade Vista \& Revista, 23(3), 109-143. Doi:

https://doi.org/10.1017/CBO9781107415324.004. 
Spence, A.M (1973). Job market signalling. Quarterly Journal of Economics, 87(3), 355-374, 1973. Doi: $10.2307 / 1882010$.

Tang, T. (2006). The Value Relevance of Book-Tax Differences: An Empirical Study in China's Capital Market. The Australian National University. Doi: 10.2139/ssrn.897120.

Tang, T., \& Firth, M. (2011). Can book-tax differences capture earnings management and tax management? Empirical evidence from China. The International Journal of Accounting, 46(2), 175-204. Doi: http://dx.doi.org/10.1016/j.intacc.2011.04.005.

Watts, R. L.; Zimmerman, J. L (1986). Positive accounting theory, Upper Saddle River, Prentice Hall. 